\title{
MORTALITY MODELLING AND FORECASTING: A REVIEW OF METHODS
}

\author{
By H. Booth AND L. Tickle
}

\begin{abstract}
Continuing increases in life expectancy beyond previously-held limits have brought to the fore the critical importance of mortality forecasting. Significant developments in mortality forecasting since 1980 are reviewed under three broad approaches: expectation, extrapolation and explanation. Expectation is not generally a good basis for mortality forecasting, as it is subjective; expert expectations are invariably conservative. Explanation is restricted to certain causes of death with known determinants. Decomposition by cause of death poses problems associated with the lack of independence among causes and data difficulties. Most developments have been in extrapolative forecasting, and make use of statistical methods rather than models developed primarily for age-specific graduation. Methods using two-factor models (age-period or age-cohort) have been most successful. The two-factor Lee-Carter method, and, in particular, its variants, have been successful in terms of accuracy, while recent advances have improved the estimation of forecast uncertainty. Regression-based (GLM) methods have been less successful, due to nonlinearities in time. Three-factor methods are more recent; the Lee-Carter age-periodcohort model appears promising. Specialised software has been developed and made available. Research needs include further comparative evaluations of methods in terms of the accuracy of the point forecast and its uncertainty, encompassing a wide range of mortality situations.
\end{abstract}

\section{KEYWORDS}

Mortality; Forecasting; Modelling; Lee-Carter; GLM; $p$-splines; Extrapolation; Uncertainty; Cohort; Decomposition; Cause of Death; Software

\section{CONTACT ADDRESS}

Heather Booth, Australian Demographic and Social Research Institute, Coombs Building 9, Australian National University, ACT 0200, Australia. E-mail: heather.booth@anu.edu.au

\section{INTRODUCTION}

Mortality modelling has a very long history. Numerous models have been proposed since Gompertz published his law of mortality in 1825. Mortality forecasting is a more recent endeavour. Only two decades ago, the methods in use were relatively simple and involved a fair degree of subjective judgement; for a review see Pollard (1987). It is only in the last 15 years or so that more sophisticated methods have been developed and applied. These have not, on the whole, made use of models developed principally for agespecific graduation. Instead, actuaries and demographers have made increasing use of standard statistical methods. The introduction of stochastic 
methods has the major advantage of producing a forecast probability distribution rather than a deterministic point forecast.

Most methods of mortality forecasting are extrapolative; they make use of the regularity typically found in both age patterns and trends over time. This approach includes the traditional and relatively simple extrapolation of aggregate measures, such as life expectancy, as well as the newer and more complex methods, such as the Lee-Carter method. A second approach (explanation) makes use of structural or epidemiological models of mortality from certain causes of death, where the key exogenous variables are known and can be measured; the classic example is the dependence of lung cancer on tobacco smoking. In a third approach (expectation), forecasts are based on the subjective opinions of experts involving varying degrees of formality.

This paper reviews the main methodological developments in mortality modelling and forecasting since 1980. It includes developments in each of the three approaches. The review updates and elaborates previous reviews of mortality forecasting. These include Keyfitz (1982), Pollard (1987), Murphy (1990), Tuljapurkar \& Boe (1998), Pitacco (2004) and Wong-Fupuy \& Haberman (2004); see also the collections of Tabeau et al. (2001a), Bengtsson \& Keilman (2003) and Keilman (2005). The paper draws on, and updates, the wider-ranging review of demographic forecasting by Booth (2006), adding a more in-depth focus on mortality modelling and forecasting methods, particularly extrapolative methods, for an actuarial readership. Although some applications are mentioned, the focus of the paper is methodological. The paper concentrates on methods used with good quality data, as available in developed countries, with only brief mention of methods more suitable for the poorer data environment of the developing world.

The paper is organised as follows. Section 2 discusses the considerations involved in mortality forecasting, including many of the decisions and the judgements which must be made. Section 3 provides an overview of the three broad approaches to forecasting. Sections 4 to 6 discuss, in greater detail, the most important methods in mortality forecasting, organised according to the models employed: this includes the most successful parameterisation functions (Section 4), the Lee-Carter method and its variants and extensions (Section 5), and regression-based methods within the GLM framework (Section 6). Section 7 addresses cohort models, while Section 8 discusses the role of decomposition by cause of death in forecasting overall mortality. Section 9 focuses on senescent mortality. Section 10 addresses the estimation of uncertainty in mortality forecasts. Finally, Section 11 draws conclusions and suggests further research.

\section{Forecasting Considerations}

Many judgemental decisions are involved in forecasting mortality. In fact, 
judgement is required at almost every stage (Alders \& De Beer, 2005). One of the most fundamental considerations is the measure to be forecast, which may depend on the purpose of the forecast and data availability. In most cases, sex-specific mortality rates (or probabilities) are of primary interest, along with derived life tables. When only life expectancy is forecast, more often the case in developing countries, an appropriate model life table can be used to provide age-specific detail. Where forecast numbers of deaths are of interest, they are best derived from forecast mortality rates through population forecasting (see Booth, 2006).

Mortality measures may refer to overall mortality or be decomposed by cause of death (see Section 8). In addition, the level of disaggregation, for example by spatial or socio-economic factors, should be considered. Whether disaggregated rates are stable or changing, changes in aggregate rates are attributable to changes in population composition arising from subgroup heterogeneity. Subgroups with higher growth rates come to dominate, resulting in increased average growth rates; similarly, a subcohort with high mortality rates will diminish in relative size, giving rise to declining average rates (Vaupel \& Yashin, 1985). However, in the context of recurrent events among interacting subgroups, the selection effects of heterogeneity are less clear (Rogers, 1992). Unrecognised heterogeneity from insufficient disaggregation may limit the use of extrapolation or lead to large forecast errors.

Mortality forecasting will generally involve the specification of an underlying model of the data and a model for forecasting. These models, referred to throughout this paper as the underlying model and the forecasting model respectively, may be distinct or integrated into a single framework. Three variables or factors, namely age, period (or time) and cohort, are usually employed to classify the underlying model as zero, one, two or threefactor (Tabeau, 2001), and this classification is used here to structure the discussion. Zero-factor models are simply an aggregate measure or an agespecific rate (where each age is treated independently); in this case, there is no specified underlying model. One-factor models treat mortality rates (period or cohort) as a function of age, permitting advantage to be taken of their regularity across age and, in forecasting, of the stability of age patterns over time. Two-factor models usually take age and period into account; most recent methods of mortality forecasting employ such models. Alternatively, age and cohort may be modelled (see Section 7; the discussion of models in Sections 4 to 6 is essentially in terms of period data). Threefactor (or APC) models express rates as a function of age, period and cohort (see Section 7).

A major problem for age-specific forecasting is high dimensionality, ${ }^{1}$

\footnotetext{
${ }^{1}$ Dimensionality refers to the total number of data 'cells' which are modelled, equal to the product of the numbers of categories for the factors classifying the data.
} 
especially when single years of age are used. Models are widely used to reduce the dimensionality problem by representing the data more parsimoniously. Parsimonious models avoid over-parameterisation (correlated parameters) and associated complications for forecasting. Parametric or non-parametric models can be used. Parametric models include parameterisation functions such as the laws of mortality, and models within the generalised linear modelling (GLM) framework. Splines are increasingly used in dimensionality reduction, their flexibility ensuring a good fit. Non-parametric methods are also used: principal components approaches address the dimensionality problem by extracting age patterns from the data, while relational models replace the age scale by an empirically-derived exogenous standard.

An important criterion in selection of the underlying model is parameter interpretability. For forecasting, it is generally advantageous if the underlying model parameters have easily-understood interpretations, such as the modal age at death or the speed at which mortality rates change. Meaningful interpretation assists in assessing the validity of the trend in the parameter and its continuation into the future. Where ease of interpretation is not the case, it may be possible to reparameterise the function in more meaningful terms (e.g. Carrière, 1992), though it is noted that reparameterisation has not been widely used in mortality modelling.

Transformation of the data is widely employed to assist modelling. The use of logarithms of rates is common in mortality modelling, one advantage in forecasting being that rates are necessarily positive. Mortality reduction (or improvement) factors, ${ }^{2}$ traditionally used by actuaries, offer the same advantage. Brass (1971) used the logit transformation:

$$
\operatorname{logit}\left(1-s_{x}\right)=\frac{1}{2} \ln \left(\frac{1-s_{x}}{s_{x}}\right)
$$

where $s_{x}$ is the probability of surviving from birth to exact age $x$, to achieve approximate linearity in relating observed to standard age patterns. Heligman \& Pollard (1980) experimented with various measures. Wilmoth (1990) used a transform based on age-specific probabilities of death $q_{x}$, which approximates log hazard rates:

$$
f_{x}=\log \left(\frac{q_{x}}{1-\frac{1}{2} q_{x}}\right) \approx \log \mu_{x+\frac{1}{2}} .
$$

Other useful transformations, or link functions, are considered by Renshaw

\footnotetext{
${ }^{2}$ The $n$-year mortality reduction factor is the ratio of the age-specific death rate at times $t+n$ and $t$.
} 
\& Haberman (2000). In an innovative approach, de Jong \& Marshall (2007) adopt the Wang transform $z_{x}=\Phi^{-1}\left(s_{x}\right)$, where $\Phi$ denotes the cumulative normal distribution (Wang, 2000).

Closely related to selection of the underlying model is determination of the forecasting approach (extrapolation, explanation or expectation) and the specific forecasting method. The choice may depend on several criteria, including data availability, the purpose of the forecast and the forecast horizon. For long-term forecasting, extrapolative time series methods are generally used, requiring lengthy series of data. The forecast accuracy of a method is also an important consideration. A distinction should be made between model fit and forecast accuracy, as in-sample errors are not necessarily a good guide to forecast errors. For long-term forecasting, in particular, the choice between models cannot reliably be based on historical goodness of fit. Ideally, out-of-sample or ex-post forecast errors should be examined using historical data. Two related considerations are the choice of measure used in the measurement of forecast accuracy and the specification of an appropriate loss function (Ahlburg, 1995; Booth et al., 2006; Pedroza, 2006).

User acceptability has also been raised as a criterion in method selection (e.g. Long, 1995). An argument sometimes posed by official statisticians is that users are ill-equipped to understand output from more complex methods, notably those producing probabilistic prediction intervals. This may partly explain the reluctance of official statistical agencies to choose statistical methods over expert-opinion-based scenarios in forecasting mortality for population projection purposes. It should be noted that the ability of users to understand the concept of prediction intervals has not, to our knowledge, been formally tested.

Once the choice of method has been made, parameters are estimated. Parameter estimates may be derived solely from the data or, alternatively, a Bayesian approach may be used in which priors ${ }^{3}$ are formally incorporated. In the mortality forecasting context, Bayesian approaches have been used to impose smoothness (Czado et al., 2005; Girosi \& King, 2006), to allow for pooling of information across countries (Girosi \& King, 2006), to improve the estimation of forecast uncertainty (Pedroza, 2006) and to allow for missing observations (Pedroza, 2006). Bayesian methods require the detailed specification of priors, which may not be straightforward.

\section{Approaches to Forecasting}

The three general approaches to mortality forecasting mentioned above

\footnotetext{
${ }^{3}$ A prior, or prior distribution, summarises what is known about a variable in the absence of observations.
} 
are described in broad terms in this section. The most commonly used methods are described in greater detail in Sections 4 to 6. In practice, the distinctions between these approaches are not always clear-cut.

\subsection{Expectation}

Expectations have often been used in mortality forecasting in the form of expert opinion: an assumed forecast or scenario is specified, often accompanied by alternative high and low scenarios (see Section 10). Most official statistical agencies have given precedence to this approach (Waldron, 2005), though several are now adopting the extrapolative approach. Actuaries have also relied heavily on expectation in the past, but are now moving towards more sophisticated extrapolative methods (Continuous Mortality Investigation Bureau, 2002, 2004, 2005, 2006, 2007).

Traditionally, a commonly-used method has been targeting of life expectancy where a value is assumed for a future date with a specified path (Pollard, 1987; Olshansky, 1988). More detailed expectations have also been used. The United States Social Security Trustees use judgement to adjust trends in cause- and age-specific death rates: to reflect a reasonable path of future mortality improvement (Waldron, 2005, p17); the resulting life expectancy forecasts are widely regarded as too low (Lee, 2000; Tuljapurkar et al., 2000; Bongaarts, 2006). The U.S. Census Bureau assumes convergence to long-term target life tables, with Lee-Carter life expectancy forecasts (see Section 5) used as benchmarks and expert opinion used to set the relative speed of mortality decline by age (Hollmann et al., 2000).

Targeting has also traditionally been applied to age-specific mortality reduction factors. The Continuous Mortality Investigation Bureau (CMIB) of the United Kingdom Institute of Actuaries and Faculty of Actuaries has projected the proportion of lives of exact age $x$ who die before attaining exact age $x+1, q_{x}$, from year zero by multiplying by the $t$-year reduction factor $R F(x, t)$, where:

$$
R F(x, t)=\alpha(x)+[1-\alpha(x)] \cdot\left[1-f_{n}(x)\right]^{t / n}
$$

and $\alpha(x)$ and $f_{n}(x)$ represent, respectively, the ultimate reduction factor and the proportion of the total decline $(1-\alpha(x))$ assumed to occur in $n$ years. The approach embodies an exponential decline in mortality over time to the asymptotic value $\alpha(x)$, and uses expert opinion to set the targets $\alpha(x)$ and $f_{n}(x)$. The ' 80 ' and ' 92 ' Series life tables (Continuous Mortality Investigation Bureau, 1990, 1999) are based on this method with different parameter values. A similar approach is used by the U.S. Society of Actuaries, but with no limiting reduction factor (equivalent to $\alpha(x)=0$ ). Wong-Fupuy \& Haberman (2004) provide further details of U.K. and U.S. applications in life insurance and pensions. The U.K. Government Actuary's Department has used age-specific target reduction factors with exponential convergence and a 
cohort approach applied to certain generations (Government Actuary's Department, 2001, 2006). Denton et al. (2005) used targeting to define 15 scenarios combining five target life tables with varying maximum ages at death and three patterns of change.

The advantage of expert opinion is the incorporation of demographic, epidemiological and other relevant knowledge, at least in a qualitative way. The disadvantage is its subjectivity and potential for bias. The conservativeness of expert opinion with respect to mortality decline is widespread, in that experts have generally been unwilling to envisage the long-term continuation of trends, often based on beliefs about limits to life expectancy. In the U.S.A., expert opinion has been found to systematically forecast smaller declines than both extrapolative methods and what actually occurred (Alho \& Spencer, 1990; Lee \& Miller, 2001; Waldron, 2005). U.K. projections have also underestimated mortality improvements (Shaw, 1994; Murphy, 1995; Continuous Mortality Investigation Bureau, 2004). In Australia, the use of reduced post-short-term rates of mortality decline has repeatedly resulted in the underestimation of life expectancy in the longer term.

It has, in fact, been found that expert opinion is subject to 'assumption drag', where expectations tend to lag rather than lead actual experience (Ahlburg \& Vaupel, 1990). One way to reduce this bias and to draw on wider expertise is to average the opinions of several experts using Delphi forecasting methods (e.g. Lutz \& Scherbov, 1998). Bias may persist because of 'expert flocking', resulting from the common information base and a desire to conform (Alho, 2005); greater emphasis has recently been placed on expert argument (rather than opinion) to increase the diversity of expectations (Lutz et al., 1999, 2004).

Expert expectations refer to population-level behaviour based on historical data and research and are suited to long-term forecasting. For very short-term forecasting, individual expectations might be considered; such an approach has been used in fertility forecasting, though with limited success (see Booth, 2006). The expectations of individuals about their own health status have been shown to be a good predictor of death (Idler \& Benyamini, 1997), and personal estimates of the probability of survival to a certain age have been shown to be consistent with life table estimates (Hauser \& Willis, 2005). While this approach is clearly limited, the individual heterogeneity in expectations may provide useful information for modelling and probabilistic forecasting.

\subsection{Extrapolation}

As already noted, extrapolation is the basis of most mortality forecasting methods. Extrapolative methods assume that future trends will essentially be a continuation of the past. In mortality forecasting, this is usually a reasonable assumption because of historical regularities. However, exceptions 
do occur: examples include temporary increases in young adult male mortality due to deaths from AIDS, recent fluctuations in Russian mortality and the period of stagnation in Australian mortality in the 1960s. This discussion of extrapolative methods progresses from simple linear extrapolation to methods based on two-factor (age-period) models. Age-cohort and three-factor (APC) models used in extrapolative forecasting are discussed in Section 7.

Among the simplest methods is the linear continuation of the trend in life expectancy. As White (2002) has shown, historical trends suggest that such a method can be expected to be accurate. Despite this, a continuing linear trend has rarely been forecast beyond the short-term future (as discussed in Section 3.1). The independent linear extrapolation of the logarithms of age-specific rates, equivalent to assuming constant age-specific mortality reduction factors, has often been applied (Pollard, 1987). Reduction factors, or fractions of reduction factors, may be directly extrapolated (Goss et al., 1998); Denton et al. (2005) used log-linear extrapolation. Golulapati et al. (1984) forecast Australian cohort mortality by linear extrapolation of Brass logit transforms (see also Pollard, 1987). Non-linear extrapolation may be used by assuming an appropriate functional form, such as the logistic.

Time series methods (Box et al., 1994) are commonly used in extrapolative forecasting. Time series models have the advantage of being stochastic, enabling the calculation of the probabilistic prediction interval for the forecast value. In the case of a zero-factor underlying model, such as a time series of life expectancy or an age-specific rate, the series itself is modelled and forecast. For one and two-factor models, the time series are the fitted parameters of the underlying model, for example the eight parameters of the Heligman-Pollard model or the single time parameter of the Lee-Carter model. In mortality forecasting, univariate ARIMA modelling has commonly been used. For multiple parameters, the simultaneous forecasting of parameters taking interdependencies into account is the ideal; this is achieved by multivariate ARIMA modelling. Though developed for shortterm forecasting, time series methods have increasingly been used for longterm mortality forecasting. Alho \& Spencer (2005, p242) recommend that the data series should always be longer than the forecast horizon, and preferably two to three times as long.

Time series forecasts based on zero-factor underlying models are relatively uncommon. Denton et al. (2005) forecast aggregate mortality in this way. Bell (1997) applied a simple random walk with drift model separately to the logarithms of each age-specific rate, and found that forecast accuracy was at least as good as more complex methods such as Lee-Carter. A major disadvantage of such an approach is that the independent forecasting of mortality at each age may lead to implausible age patterns, especially in the long term. To address this problem, Denton 
et al. (2005) forecast first differences of age-specific log death rates as a system of cross-correlated time series models; estimation was achieved using an iterated form of the seemingly unrelated regression estimator (SURE).

Among the one-factor models ${ }^{4}$ used in mortality forecasting are parameterisation functions (discussed in Section 4) and the Brass relational model (Brass, 1971, 1974) which was developed for estimation purposes in data-poor contexts, but can be used more widely. The two-parameter relational model expresses the logit transformation of the observed survival function as a linear function of the logit of an empirical standard schedule. It is thus a special case of graduation by reference to a standard table (Benjamin \& Pollard, 1980). Fitting to annual data yields time series of the two parameters may be forecast using time series methods. Keyfitz (1991) applied the method to Canadian data with limited success (see also Pollard, 1987). Extensions of the model include Zaba (1979) and Ewbank et al. (1983) who developed separate four-parameter models to increase flexibility at the youngest and oldest ages; see also Zaba \& Paes (1995). Congdon (1993) fitted the Zaba model to mortality for Greater London in 1971 to 1990, obtaining relatively clear trends for three of the four parameters, and forecast all parameters using univariate ARIMA models.

A two-factor model used in mortality forecasting is the Lee-Carter model (Lee \& Carter, 1992). This type of model can be estimated using principal components, whereby matrix decomposition identifies independent mortality components or age patterns and their importance over time. In forecasting, the estimated age parameters are assumed fixed and time series methods are used to extrapolate the time-varying parameters. The Lee-Carter method and related approaches are discussed in detail in Section 5. In a similar approach, the panel data model of Babel et al. (2008) expresses the logarithm of the mortality reduction factor as the sum of stochastically independent age and time effects; time series methods are used to model the time effect while the age effect is assumed fixed.

An alternative two-factor model is the bivariate (age and time) regression model within the GLM framework. The essential difference between GLM and Lee-Carter models is that in GLM time is an explicit covariate while in Lee-Carter time is a factor represented by the series. Forecasting in the GLM approach is achieved simply by using appropriate time values. The GLM approach is discussed in Section 6.

Dynamic parameterisation functions constitute a special two-factor case within the GLM framework. Such models adopt an initial static base

\footnotetext{
${ }^{4}$ Spline models involve many parameters without demographic interpretation, making them largely unsuitable for forecasting in the one-factor context.
} 
parameterisation function of the age pattern (see Section 4), thereby reducing the number of parameters to be estimated, and replace each parameter by a function of time. For example, in the dynamic parameterisation model of Tabeau et al. (2001b), the parameters of the modified Heligman-Pollard model are linear or non-linear functions of time. The exact trend functions are determined when fitting the model. In some cases, similar models of overall mortality fit almost equally well, but their forecasts differ considerably; much depends on the assumptions made in extrapolating the trend functions especially in highly non-linear parameterisation functions (Tabeau et al., 2001).

\subsection{Explanation}

Explanatory methods of mortality forecasting are based on structural or causal epidemiological models of certain causes of death involving disease processes and known risk factors. Thus use is made of valuable medical knowledge and information on behavioural and environmental change (Gutterman \& Vanderhoof, 1998). The main advantage of the explanatory approach is that feedback mechanisms and limiting factors can be taken into account.

In practice, the explanatory approach to forecasting has yet to be fully developed. The relationships between risk factors and mortality are imperfectly understood, making their use in forecasting less than reliable. The main use of existing epidemiological models is in the simulation of the effect on morbidity and mortality of policy changes affecting the risk factors, rather than in forecasting per se.

Many of the models used in explanatory forecasting are regression-based and therefore fit within the GLM framework. ${ }^{5}$ They differ from regressionbased extrapolative models in that they incorporate explanatory variables or risk factors, which are either lagged or forecast. When structural models are based exclusively on exogenous lagged risk factors, forecast horizons are limited to the shortest lag time. While extrapolation of the risk factors extends the forecast horizon, they may be no less difficult to forecast than mortality directly. Thus explanatory methods are generally limited to shortterm forecasting.

In some cases, an explanatory model is used in conjunction with expectation (Section 3.1) in the specification of future scenarios, for example, the use of assumed future smoking patterns in a lung cancer model (Alderson \& Ashwood, 1985). The explanatory models developed under the

\footnotetext{
${ }^{5}$ Dynamic multistate or macrosimulation models also fall under the explanatory approach. These take population structure into account to forecast numbers of events, and may employ as input either static or forecast rates, the latter being obtained by a separate model. For examples, see Van Den Berg Jeths et al. (2001) and Van Genugten et al. (2001).
} 
WHO Global Burden of Disease Study have also been used in scenario forecasting (e.g. Murray \& Lopez, 1997).

Structural models involving multivariate autoregression have been used to relate lifestyle and other risk factors to functional status and mortality at older ages (Manton et al., 1991; Manton et al., 1992). This approach achieved some improvement in the short term over methods involving traditional time series and expert opinion. In the longer term, however, forecasting potential is limited by the short time series of risk factors, the large number of parameters and the presence of non-linear interactions.

Girosi \& King (2006) extend the use of structural models in mortality forecasting to developing countries, using Bayesian methods. Linear ageperiod regression models are used to relate cause-of-death-specific mortality to known covariates. The covariates may differ by age, and may be lagged, observed, exogenous variables or forecasts of reliable longer time series. Known similarities among (sub)populations and smoothness over both age and time are incorporated as priors, based on empirical evidence or informed judgement.

It should be noted that decomposition of overall mortality by cause of death does not constitute explanation, although decomposition permits explanatory models to be used. Decomposition by cause of death is discussed in relation to forecasting overall mortality in Section 8.

\section{Parameterisation Functions}

Parameterisation functions, also known as laws of mortality, are onefactor models which seek to parsimoniously represent the age pattern of mortality. The Heligman-Pollard model is a well-known example. Though parameterisation functions have been widely applied in mortality graduation (Forfar et al., 1988), their use in mortality forecasting is more limited. An advantage of parameterisation functions for forecasting is the smoothness of forecast rates across age. Bell (1997) noted familiarity and interpretability as additional advantages of this approach. In most applications, these models have been treated as deterministic.

Forecasting with parameterisation functions involves repeated fitting to annual data, thereby obtaining a time series of each model parameter. These parameter series are forecast by time series methods. Ideally, multivariate time series methods are used to take account of any interdependencies among parameters. In practice, erratic parameter time series and interdependencies (over-parameterisation) present serious difficulties for forecasting and limit forecast horizons: forecast age patterns may be implausible, and, if interdependencies are not taken into account, forecast prediction intervals will be inaccurate. The magnitude of the approximation error is also a disadvantage (Bell, 1997). 


\subsection{Heligman-Pollard Model}

Among the many parameterisation functions which have been proposed (for a comprehensive list see Tabeau et al., 2002; see also Forfar, 2004), the Heligman-Pollard model (Heligman \& Pollard, 1980) is among the most well known. The eight-parameter model has three terms capturing the age pattern of mortality in childhood, young adulthood (the accident hump) and senescence, respectively:

$$
\frac{q_{x}}{p_{x}}=A^{(x+B)^{C}}+D \exp \left[-E(\ln x-\ln F)^{2}\right]+G H^{x}
$$

where $p_{x}=1-q_{x}$, and $A$ to $H$ are the eight parameters. Each term takes positive values only at relevant ages, and the whole function is estimated in one step. The model has been found to fit well to a range of populations (Mode \& Busby, 1982; Hartmann, 1987; Kostaki, 1988; Rogers \& Gard, 1991).

However, only Forfar \& Smith (1987) have found the Heligman-Pollard model useful for forecasting. One reason for this might be found in the high correlations between parameters, particularly for male mortality (e.g. Hartmann, 1987); these correlations also compromise parameter interpretability. Difficulties have also been encountered in determining the best base period for projecting the parameters when using simple methods (Pollard, 1987; Keyfitz, 1991). Using univariate time series models for the eight parameter series obtained from fitting to U.S. data for 1900 to 1975, McNown \& Rogers (1989) forecast mortality for 1976 to 1985 with only 'reasonable accuracy' (McNown \& Rogers, 1992, p413).

\subsection{Multiexponential Model}

The multiexponential model was first developed for modelling migration. Rogers \& Planck (1983) applied the four-term nine-parameter version to mortality. The model comprises a constant, exponentially declining child mortality, a double exponential accident hump (the Coale \& McNeil (1972) function) and Gompertzian senescent mortality:

$$
m_{x}=a_{0}+a_{1} \exp \left(-\alpha_{1} x\right)+a_{2} \exp \left\{-\alpha_{2}(x-\mu)-\exp [-\lambda(x-\mu)]\right\}+a_{3} \exp \left(-\alpha_{3} x\right)
$$

where: $m_{x}$ is the central mortality rate at age $x ; a_{0}, a_{1}, a_{2}$ and $a_{3}$ are scale or level parameters; and $\alpha_{1}, \alpha_{2}, \alpha_{3}, \mu$ and $\lambda$ define the mortality profile.

Rogers \& Little (1994) found slightly poorer fits than the HeligmanPollard model. Like Heligman-Pollard, the multiexponential is of limited use in forecasting. McNown, Rogers \& Little (1995) found interdependencies among parameters; in forecasting, five parameters were fixed and four were modelled by three univariate ARIMA processes and a bivariate autoregressive model. McNown \& Rogers (1992) forecast total and five 
cause-specific mortalities by fixing six parameters and modelling only the level parameters, $a_{1}, a_{2}$ and $a_{3}$, by univariate ARIMA models, giving reasonably accurate forecasts for the following decade.

\subsection{Other Models}

Several parameterisations have been shown to provide a better fit to the age distribution of mortality than either the Heligman-Pollard or multiexponential models, but, to our knowledge, have not been employed in forecasting. Such models are included here, as gains in forecast accuracy might be obtained by their adoption.

Carrière (1992) proposed a three-term model with eight interpretable parameters:

$$
s_{x}=\psi_{1} \exp \left\{-\left(\frac{x}{m_{1}}\right)^{\frac{m_{1}}{\sigma_{1}}}\right\}+\psi_{2}\left[1-\exp \left\{-\left(\frac{x}{m_{2}}\right)^{-\frac{m_{2}}{\sigma_{2}}}\right\}\right]+\psi_{3} \exp \left\{e^{-\frac{m_{3}}{\sigma_{3}}}-e^{\frac{x-m_{3}}{\sigma_{3}}}\right\}
$$

where: $s_{x}$ is the probability of surviving to exact age $x, x>0 ; \psi_{1}$ is the probability of dying from 'childhood causes'; $\psi_{2}$ is the probability of dying from 'teenage causes', $\psi_{3}=1-\psi_{1}-\psi_{2}$ is the probability of dying from 'adult causes'; and $m_{1}, m_{2}, m_{3}, \sigma_{1}, \sigma_{2}$ and $\sigma_{3}$ are location and dispersion parameters.

This model gave a better fit to U.S. mortality than the Heligman-Pollard model. Though similar to Heligman-Pollard, the Carrière model has several important advantages. The parameters have a clearer interpretation, and the location and scale parameters provide insightful information. The use of a mixture of survival functions is equivalent to a multiple-decrement life table; and the generalised framework can accommodate extra terms and other functions. Carrière (1992) found that for U.S. female mortality a four-term model with eleven parameters gave significant improvements over a reduced eight-parameter model. The flexibility of this model has potential advantages in forecasting.

Siler (1983) proposed a five-parameter model which was found to fit better than either the Heligman-Pollard or Mode-Busby eight-parameter models (Gage \& Mode, 1993); only the ten-parameter Mode-Jacobsen (1984) model provided a better fit. The Siler model has three independent terms describing mortality during 'immaturity', adulthood and senescence. The survivorship probabilities are multiplicative:

$$
s_{x}=\exp \left\{\left(-\frac{a_{1}}{b_{1}}\right)\left[1-\exp \left(-b_{1} x\right)\right]\right\} \cdot \exp \left(-a_{2} x\right) \cdot \exp \left(\frac{a_{3}}{b_{3}}\right)\left[1-\exp \left(b_{3} x\right)\right]
$$

where $s_{x}$ is the probability of surviving to exact age $x, x>0$, and $a_{1}, a_{2}, a_{3}$, $b_{1}$ and $b_{3}$ are location and dispersion parameters. Siler successfully fitted the 
model to historic data largely for the period before the emergence of the accident hump and with widely varying life spans.

Hannerz (1999; 2001a) also proposed a five-parameter model which fitted recent Swedish female mortality better than models including a term for the accident hump. The female model is:

$$
1-s_{x}=\exp \left(G_{x}\right)
$$

where $s_{x}$ is the probability of surviving to exact age $x, x>0$, and

$$
G_{x}=a_{0}-\frac{a_{1}}{x}+\frac{a_{2}}{2} x^{2}+\frac{a_{3}}{c}[\exp (c x)]
$$

where $G_{x}$ is an empirically derived representation of the logit transform of $\left(1-s_{x}\right), a_{0}$ is a level parameter and $a_{1}, a_{2}$ and $a_{3}$ are profile parameters. For males, the persistence of the accident hump necessitated an additional term involving three parameters to capture excess mortality at young adult ages (Hannerz, 2001b). The male model is:

$$
1-s_{x}=\alpha \frac{\exp \left(G_{x}^{1}\right)}{1+\exp \left(G_{x}^{1}\right)}+(1-\alpha) \frac{\exp \left(G_{x}^{2}\right)}{1+\exp \left(G_{x}^{2}\right)}
$$

where $\alpha$ is a scale parameter and

$$
\begin{aligned}
& G_{x}^{1}=a_{0}-\frac{a_{1}}{x}+\frac{a_{2}}{2} x^{2}+\frac{a_{3}}{c}[\exp (c x)] \\
& G_{x}^{2}=a_{4}-\frac{a_{5}}{x}+\frac{a_{2}}{2} x^{2}+\frac{a_{3}}{c}[\exp (c x)]
\end{aligned}
$$

where $a_{4}$ is a level parameter and $a_{5}$ is a profile parameter.

Hannerz (2001c) combined the features of relational models with these parameterisation functions and model life tables in a regression model. The advantage of this approach is that there is no need to choose between these methods; rather, use is made of the features of all three.

\section{LeE-CARTer VARiants AND Extensions}

The principal components approach to mortality forecasting came to prominence through the work of Lee \& Carter (1992), although it had been applied earlier (e.g. Bell \& Monsell, 1991). In contrast to parametric approaches which specify the functional form of the age pattern of mortality in advance, principal components approaches estimate the age pattern from 
the data. Forecasting is by extrapolation of the time-related parameters using time series methods.

Lee-Carter is now the dominant method of mortality forecasting. LeeCarter or its variants have been applied to populations in the G7 countries (Tuljapurkar et al., 2000), Australia (Booth \& Tickle, 2003, 2004), Japan (Wilmoth, 1996) and Sweden (Lundstrom \& Qvist, 2004) among others, and Lee-Carter benchmarks are used by the U.S. Census Bureau for its long-term forecasts of life expectancy (Hollmann et al., 2000).

The underlying two-factor Lee-Carter model is:

$$
\ln m_{x, t}=a_{x}+b_{x} k_{t}+\varepsilon_{x, t}
$$

where: $m_{x, t}$ is the central mortality rate at age $x$ in year $t ; a_{x}$ is average (over time) $\log$-mortality at age $x ; b_{x}$ measures the response at age $x$ to change in the overall level of mortality over time; $k_{t}$ represents the overall level of mortality in year $t$; and $\varepsilon_{x, t}$ is the residual.

Unique estimates of $b_{x}$ and $k_{t}$ are derived using singular value decomposition (SVD) with the constraints that the estimated $b_{x}$ sum to one and the estimated $k_{t}$ sum to zero. Lee \& Carter incorporated an adjustment to the estimated $k_{t}$ so that fitted deaths match observed total deaths in each year; this gives greater weight to ages at which deaths are high thereby partly counterbalancing modelling on the logarithmic scale (Lee, 1992). The adjusted estimated $k_{t}$ is modelled and forecast using Box-Jenkins time series methods. In almost all applications, including the original study of U.S. data (Lee \& Carter, 1992), the random walk with drift has been found to be applicable:

$$
k_{t}=k_{t-1}+d+e_{t}
$$

where $d$ is the drift parameter and $e_{t}$ is an error term. Forecast mortality rates are derived using estimated $a_{x}$ and $b_{x}$ (which are assumed invariant over time) and forecast $k_{t}$.

Two variants on the original Lee-Carter method have been developed. Lee \& Miller (2001) proposed three modifications: the fitting period was restricted to the latter half of the twentieth century to reduce structural shifts; adjustment of $k_{t}$ was by matching life expectancy; and 'jump-off error' was eliminated by forecasting forward from observed (rather than fitted) rates. The Lee-Miller variant has now been widely adopted as the standard Lee-Carter method. Booth et al. (2002) modified the method after finding historical departures from linearity in the Australian mortality decline; their method determines an optimum fitting period based on the assumption of a linear recent trend, and adjusts $k_{t}$ by fitting to the age distribution of deaths (a conditional maximum likelihood procedure). A twenty-population evaluation of the forecasting accuracy of the original method and these two 
variants over a 15-year forecast period found that the Lee-Miller and Booth-Maindonald-Smith variants produced roughly equal improvements over Lee-Carter (Booth et al., 2005).

The Lee-Carter model can be extended to include higher order terms (the $p$-term model is shown) thereby allowing for greater flexibility in forecasting change:

$$
\ln m_{x, t}=a_{x}+b_{x}^{1} k_{t}^{1}+b_{x}^{2} k_{t}^{2}+\cdots+b_{x}^{p} k_{t}^{p}+\varepsilon_{x, t} .
$$

Higher order terms were modelled by Booth et al. $(2001,2002)$ and modelled and forecast using univariate ARIMA processes by Renshaw \& Haberman (2003a). The extended form has close similarities to the principal components approach used by Bell \& Monsell (1991). Bell (1997) discusses the similarities and differences in detail and, for short-term U.S. forecasts, demonstrates the greater accuracy (after adjusting for jump-off error) of Lee-Carter over both Heligman-Pollard and principal components using all components.

The Lee-Carter method has a number of advantages, among them simplicity. The underlying model has been shown to represent a large proportion of the variability in mortality rates in developed countries (Tuljapurkar et al., 2000). Parameters are easily interpretable and a simple random walk with drift forecast has generally been appropriate for the single extrapolated parameter. The method involves minimal subjective judgement and produces stochastic forecasts with probabilistic prediction intervals.

Improvements to the Lee-Carter estimation basis have been proposed. Wilmoth (1993) presented a weighted least squares Lee-Carter solution. He also developed a maximum likelihood estimation solution based on the assumption of a Poisson distribution of deaths; this Poisson log-bilinear model has subsequently been implemented by others (e.g. Brouhns et al., 2002; Czado et al., 2005; Koissi et al., 2006). Koissi \& Shapiro (2006) implemented a fuzzy formulation of Lee-Carter to address violations of the Lee-Carter assumption of constant error variance across age. Wolf (2004) developed a Lee-Carter variant applied to first differences in log-mortality rates which integrates estimation of the Lee-Carter and time series models. Li \& Chan (2005) proposed an outlier-adjusted Lee-Carter model which strengthens the estimation basis when the mortality index time series contains outliers from exogenous events.

A shortcoming of Lee-Carter is that it assumes that the ratio of the rates of mortality change at different ages remains constant over time (i.e. invariant $b_{x}$ ), whereas evidence of substantial age-time interaction has been found. Booth et al. (2002) partially address this problem by choosing a fitting period which optimally satisfies the model assumptions; see also Carter \& Prskawetz (2001).

Lee-Carter forecast rates lack across-age smoothness and become 
increasingly jagged over time (Girosi \& King, 2006), which is nonintuitive and may be problematic in practical applications. Czado et al. (2005) used the Poisson log-bilinear model together with Bayesian estimation to impose smoothness. Hyndman \& Ullah (2007) developed an approach based on the functional data paradigm in which data are smoothed across age prior to modelling using penalised regression splines. The method also models higher order terms and strengthens the estimation basis to allow for outliers.

Other recent advances make use of state space models (Harvey, 1989), which can be viewed as a framework for jointly modelling time series and cross-sectional data. An advantage of such integrated models is that the statistical and diagnostic properties of the entire estimation and forecasting process are well known and understood compared with those of Lee-Carter and other methods which use a staged estimation approach. De Jong \& Tickle (2006) tailor the state space framework to build in across-age smoothness using $b$-splines. Compared with Lee-Carter, the method employs fewer parameters due to the use of splines to reduce dimensionality, produces smooth forecast rates and offers the advantages of integrated estimation and forecasting.

Evaluations indicate that these newer methods perform at least as well as Lee-Carter variants in terms of forecast accuracy while also offering, to varying degrees, advantages in across-age smoothness, parsimony, integrated and robust estimation and generalisability. A twenty-population study of forecast accuracy found that the Hyndman-Ullah and de Jong-Tickle approaches gave lower average errors in forecast log mortality than the LeeMiller and Booth-Maindonald-Smith variants, though not significantly so. All four approaches gave significantly lower average errors in forecast $\log$ mortality than the original Lee-Carter method (Booth et al., 2006).

De Jong \& Marshall (2007) have proposed a new method which combines state space models and the Wang transform, which has been widely used in pricing insurance and financial risk (Wang, 2000). The approach is analogous to Lee-Carter, but makes use of a transformation which allows the assumption to be made that the mortality index affects all ages equally (equivalent to constant $b_{x}$ in the Lee-Carter model), giving a simpler basis for forecasting. Pedroza (2006) used the state space framework and Bayesian estimation, as well as developing an extension to allow for differential across-age variability.

Renshaw \& Haberman (2006) extended the Lee-Carter model to incorporate cohort effects (see Section 7).

\section{Generalised Linear Modelling}

Renshaw (1991) observed that many of the one-factor parameterisation 
functions are special cases within the GLM framework. Placing such models in the GLM context provides a unified framework and facilitates generalisations such as the extension of the models to include period (time) for forecasting. The dynamic parameterisation model (discussed in Section 3.2) is an example.

Renshaw et al. (1996) proposed a two-factor model based on an overdispersed Poisson distribution of deaths and comprising a GompertzMakeham graduation term in combination with a multiplicative age-specific trend adjustment term:

$$
\log \mu_{x, t}=\beta_{0}+\sum_{j=1}^{s} \beta_{j} L_{j}\left(x^{\prime}\right)+\sum_{i=1}^{r} \alpha_{i} t^{\prime i}+\sum_{i=1}^{r} \sum_{j=1}^{s} \gamma_{i j} L_{j}\left(x^{\prime}\right) t^{i i}
$$

where: $\mu_{x, t}$ is the force of mortality at age $x$ in year $t, \alpha_{i} ; \beta_{j}$ and $\gamma_{i j}$ are unknown parameters; $L_{j}\left(x^{\prime}\right)$ denote Legendre polynomials of degree $j$; and $x^{\prime}$ and $t^{\prime}$ are $x$ and $t$ rescaled over the interval $[-1,1]$. They found that the model provided an adequate fit to mortality for U.K. male assured lives aged 22 to 89 and of duration five and over. Sithole et al. (2000) used the same modelling structure to forecast U.K. annuitant and pensioner mortality with qualified success; the optimum fitted model parameters did not necessarily generate plausible forecasts, for which lower-order polynomials were required.

Other researchers have also found that two- or higher-degree polynomials in time are required to attain a satisfactory fit, but lead to implausible forecasts. Heathcote \& Higgins (2001a, 2001b) modelled the log-odds of lexis-parallelogram mortality at ages $40+$ by a two-factor regression involving time, a quadratic in age, an age-time interaction and up to 24 additional predictors, but naïve extrapolation gave implausible divergence by sex, necessitating the use of subjectively-adjusted coefficients. In such cases, it may be possible to use linear splines for subperiods, but this solution is restricted to short-term forecasting because turning points cannot be identified (De Beer, 1989).

Renshaw \& Haberman (2000) used GLM to model mortality reduction factors, and identified the conditions under which the underlying structure of their model is the same as that of the Lee-Carter model. They developed a GLM-based approach which parallels the Lee-Carter method, including matching observed and expected total deaths (Renshaw \& Haberman, 2003b), and adapted the Lee-Carter method for use in forecasting mortality reduction factors (Renshaw \& Haberman, 2003c). Renshaw \& Haberman (2003a) extended the Lee-Carter model to include the second SVD term to allow for 'age-specific enhancement', and compared its forecast with similarly-enhanced GLM and Poisson log-bilinear forecasts.

In an alternative approach using the GLM framework, Currie et al. 
(2004) employed $p$-splines (penalised $b$-splines) to impose smoothness on the age-period surface of the force of mortality. The forecast rates are estimated simultaneously with the fitting of the mortality surface, and are 'wellbehaved' due to the penalty attached to lack of smoothness. CMIB (2005, 2006) further discuss the features of the method. Application to U.K. male assured lives generated forecast rates that declined more slowly than in the comparable Lee-Carter forecast (Currie et al., 2004).

\section{COHORt Models}

The one and two-factor models discussed in Sections 4 to 6 may be applied to cohort data to produce models of mortality over the life course. These models and three-factor age-period-cohort (APC) models are discussed in this section.

In the case of one and two-factor models, the cohort approach has the advantage of being free of 'tempo' distortions caused by changes in timing; when mean age at death is increasing (that is, when mortality is declining), the period life expectancy measure overestimates life expectancy (Bongaarts \& Feeney, 2002). In theory, therefore, cohort models provide a better basis for forecasting than period models. In practice, however, various factors have limited their use.

The main disadvantage of all cohort models is that they involve heavy data demands; if the entire age range is of interest, data covering a century or so provide only one complete cohort and a much longer series of annual data is required for forecasting. Where data are available, as in some European countries, models of the entire age range will be limited in that they depend on the (inappropriate) experience of cohorts born in the nineteenth century (e.g. Tabeau et al., 2001b). These problems of data availability and applicability are reduced when only part of the age range is of interest.

Incomplete cohort data, i.e. data which are truncated at the current age of the cohort, may be used in forecasting if the form of the model can be specified in advance. One-factor parameterisation functions and relational models may be fitted to incomplete cohort data to provide an estimate of the cohort's experience beyond the age of truncation; because age and time are equivalent for a cohort, the estimate is also a forecast. This approach is used in the modelling of mortality at the oldest ages (see Section 9). Similarly, two-factor age-cohort models may, in theory, be used with partially incomplete cohort data, the additional factor enabling advantage to be taken of complete observations for older cohorts in estimating the complete experience of younger cohorts. However, incomplete data lead to statistical problems in modelling and to practical problems for forecasting (Brass, 1974; Bell, 1997). 
Given the limitations of cohort data, it may be preferable to make adjustments to period forecasts to obtain cohort values. Pollard (1998) proposed a simple adjustment to period life expectancy based on Gompertzian mortality and a constant rate of change over age and time. Tempo distortions in period life expectancy should also be taken into account; Bongaarts \& Feeney (2006) proposed an adjustment for such distortions, with implications for forecasting. A refinement would be to adopt the lexis parallelogram approach of Heathcote \& Higgins (2001a) in defining period rates. Other aggregate measures of mortality (Bongaarts \& Feeney, 2003; Guillot, 2003; Sanderson \& Scherbov, 2005) may be considered.

A true cohort forecast was achieved by CMIB (2006) using the $p$-spline regression method (Currie et al., 2004; see Section 6) to smooth age-cohort data (where the penalty is applied over age and year of birth) at ages $20+$. A comparable age-period forecast was also made. Out-of-sample testing suggested that the method 'would have worked well in recent years' (CMIB, 2006, p38).

Three-factor APC models encompass cohort as the third factor. However, distinguishing between age, period and cohort effects is problematic because of the identification problem; any one factor is linearly dependent on the remaining two (see Tabeau, 2001). The solution to this problem is to use three-way classification (also known as doubly-classified data or nonoverlapping cohorts) in data collection so that deaths can be allocated to lexis parallelograms, in which case the dependence does not exist (Willekens \& Baydar, 1986). Alternatively, constraints can be imposed on the model parameters (see also Van Hoorn \& De Beer, 2001). To overcome the identification problem in the absence of three-way classified data, Wilmoth (1990) developed a two-factor descriptive model involving additive age and period effects and several multiplicative interaction terms, to which a diagonal term representing the average cohort effect can also be added.

The APC model has been usefully applied in describing the past, but has been considered less useful in forecasting. In a review of APC models, Tabeau (2001) concluded that mortality forecasting based on APC models is not feasible because of the difficulty in assuming future period effects (although age and cohort effects can be assumed to be fixed), and that only in forecasts of specific diseases would sufficient epidemiological knowledge be available.

More recently, Renshaw \& Haberman (2006) have extended the LeeCarter model to produce the APC model:

$$
\ln \mu_{x, t}=a_{x}+b_{x}^{1} k_{t}+b_{x}^{2} l_{t-x}+z_{x, t}
$$

where: $\mu_{x, t}$ is the force of mortality at age $x$ in year $t ; a_{x}$ is the average of 
$\ln \mu_{x, t}$ over time; $b_{x}^{1}$ and $b_{x}^{2}$ measure the response at age $x$ to changes in $k_{t}$ and $l_{t-x}$ respectively, $k_{t}$ represents the overall level of mortality in year $t, l_{t-x}$ represents the overall level of mortality for the cohort born in year $(t-x)$, and $z_{x, t}$ is the residual. Fitted $k_{t}$ and $l_{t-x}$ parameters were forecast using univariate time series models; a multivariate approach could also be used. The model successfully captured all three main effects in U.K. mortality, representing a significant improvement over age-period and age-cohort models. Out-of-sample testing by CMIB (2007) showed that age-period LeeCarter forecasts quickly became outdated due, at least in part, to lack of recognition of cohort effects captured by the APC model. It remains to test fully the APC model, particularly its stability in response to changes in the age-range or fitting period.

Though cohort effects are generally much smaller than period effects, for some countries they are nevertheless clearly discernible. In the U.K., negative cohort effects (i.e. lower mortality) have been identified at adult ages for cohorts born during 1925 to 1945 (Willets, 2004; Willets et al., 2004) and at 65+ for earlier cohorts born after 1900 (Government Actuary's Department, 2001). Since 1992, U.K. official projections (which are derived using targets) have incorporated a cohort approach, originally for cohorts born before 1947 and extended in the most recent projections to cohorts born before 1960 (Government Actuary's Department, 2001, 2006). The U.K. Actuarial Profession has recently focused on models incorporating cohort, as outlined above (Continuous Mortality Investigation Bureau, 2005, 2006, 2007). Cohort effects have also been identified in U.S. data (McNown \& Rogers, 1989; Lee \& Carter, 1992), in French data (Wilmoth, 1990) and in Japanese data (Willets, 2004), among others.

\section{Decomposition by Cause of Death}

The forecasting of mortality by separate causes of death has been advocated from a theoretical perspective as a means of gaining accuracy in overall mortality forecasting (e.g. Crimmins, 1981), but subsequent experience has often proved otherwise. McNown \& Rogers (1992) found no consistent discernible gain in accuracy from cause-of-death decomposition using the multi-exponential model. Wilmoth (1995) demonstrated that, for proportional rates of change models including Lee-Carter, mortality forecasts based on the sum of cause-specific forecasts will always be higher than those based on overall mortality because causes of death which are slow to decline come to dominate in the long run. Using non-linear APC models for ages 60 to $85+$, Caselli (1996) found this to be true for females, but reversed for males. Using non-linear age-period models, Tabeau et al. (2001b) also found this difference between the sexes at ages 40, 60 and 80 for France, Italy and the Netherlands, but not for Norway. Alho (1991) 
discusses the conditions under which decomposition is disadvantageous and those under which it gives similar results to overall mortality forecasting.

In practice, limited value can generally be gained from decomposition by cause of death. The reasons for this include the similarity of age patterns for the main causes, the unreliability of cause-of-death reporting at older ages where most deaths occur, and the fact that cause-reduction may have minimal effect on overall mortality (Murphy, 1995). Model misspecification and the presence of leading indicators (where changes in one cause systematically precede changes in another cause) can also result in reduced forecast accuracy from decomposition (Alho, 1991). Further, the assumption that discrete diseases drive overall mortality is questionable, especially at the older ages, and the appropriate means of combining correlated causespecific measures is unclear (Stoto \& Durch, 1993). Additional limitations arise because available time series of cause-specific data are often too short for forecasting using ARIMA methods, and the parameters to be forecast are often less stable for causes of death than for overall mortality (Wilmoth, 1995). Dimensionality is also increased by decomposition. Alho (1991), Stoto \& Durch (1993), Tuljapurkar (1998) and Wilmoth (2005) discuss these and other relevant issues.

The restriction of cause-of-death decomposition to ages less than 90 (or thereabouts), as recommended by Tabeau et al. (2001b) because of problems in the identification of cause of death at older ages, is a major limitation of the approach (most deaths occur at very old ages). At younger ages, these authors advocate the selection of appropriate causes of death for different age segments, and warn against forecasting the remainder (of a group of causes) because of bias arising from misclassification of deaths by cause. In other words, for long-term forecasting in particular, they do not advocate decomposition as a means of forecasting overall mortality, recommending rather that the remainder be forecast as the difference between overall and leading cause-of-death forecasts.

Given these limitations, most official agencies and actuaries have not employed decomposition by cause of death in mortality forecasting. ${ }^{6}$ The U.K. Government Actuary's Department (2001) recommended against cause-of-death decomposition, while the CMIB (2004) stated that aggregate forecasts are more suitable for its purposes. A notable exception is the U.S. Social Security Administration (SSA) ${ }^{7}$ (Board of Trustees of the Federal Old-Age and Survivors Insurance and Disability Insurance Trust Funds, 2004), but the SSA 1999 and 2003 Technical Panels on Assumptions and

\footnotetext{
${ }^{6}$ However, analysis of past cause-of-death data often informs expert opinion in the specification of target values and trajectories towards the target (see Section 3.1).

${ }^{7}$ The age, sex and cause-specific forecasts are based on expert opinion.
} 
Methods recommended against decomposition by cause of death (Waldron, 2005). In general, the perceived advantages of decomposition are outweighed by the limitations involved.

One area where decomposition by cause of death has been used is (partial) cause-elimination and cause-delay models (Manton et al., 1980; Olshansky, 1987, 1988; e.g. Kunst et al., 2002; Le Bras, 2005). The basis of such models may be expectation through targeting and informed opinion, which has often lead to conservative forecasts of mortality decline, or explanation through epidemiological models of certain causes.

Bongaarts (2006) forecast life expectancy by decomposing mortality into three components: juvenile and, at ages 25+, background and senescent. These do not correspond to standard causes of death; such data are not used. Senescent mortality is further decomposed by attributability to smoking, based on time-dependent average proportions in developed countries. The main driver of the forecast is senescent mortality which is not attributable to smoking; juvenile and background mortality are fairly stable and relatively unimportant, while mortality due to smoking can be modelled. The approach avoids many of the limitations inherent in cause-of-death decomposition, while capturing trends in the main components of mortality.

\section{Senescent Mortality}

As mortality declines, increasing importance is placed on the function representing mortality at old ages, at which most deaths occur. The Gompertz function has been widely employed to represent senescent mortality (mortality due to ageing) (Pollard \& Valkovics, 1992; Olshansky \& Carnes, 1997), but at the oldest ages it overestimates observed rates. This bias can be addressed by embedding the Gompertz in a logistic function, thus involving an asymptote; see Thatcher et al. (1998) and Thatcher (1999) for a comparison of models.

Bongaarts (2005) employed a shifting logistic model in forecasting agespecific mortality at ages $25+$. The model is based on the one-factor parameterisation:

$$
\mu_{x}=\frac{\alpha e^{\beta x}}{1+\alpha e^{\beta x}}+\gamma
$$

where $\mu_{x}$ is the force of mortality at age $x$, and $\alpha, \beta$ and $\gamma$ are parameters representing, respectively, the level of Gompertzian mortality, the exponential rate of increase in Gompertzian mortality with age and the level of age-invariant background mortality. The first term represents the senescent force of mortality. The slope parameter $\beta$ has been shown to be (nearly) constant over time, though its value varies among populations 
(Bongaarts, 2005). The shifting logistic makes use of this fixed slope, in other words of the equivalence between senescent mortality decline over time and a shift of the senescent force of mortality schedule to older ages. In forecasting, the annual series of time-varying parameters $\alpha$ and $\gamma$ are independently extrapolated, and a fixed $\beta$ is assumed. In modelling senescent mortality improvements by a fixed shift in the mortality schedule over age, rather than a fixed pattern of decline in age-specific rates (as in Lee-Carter), the age-pattern of mortality remains plausible even for longer-term forecasts. A shifting logistic has been used in conjunction with the LeeCarter method in long-term U.N. forecasts (United Nations, 2004; Buettner \& Zlotnik, 2005).

In addition to modelling considerations, difficulties arise because data at the oldest ages are often problematic (Kannisto, 1994; Kannisto et al., 1994; Tuljapurkar \& Boe, 1998). Where data are truncated, modelling of the oldest ages is necessary. For this, existing model life tables are of limited use for low-mortality populations, because the age range does not extend beyond 100 years (if that) and maximum life expectancies have been surpassed (for example, 76.6 years for males and 80.0 for females in the Princeton life tables (Coale \& Guo, 1989)).

The Coale \& Kisker (1990) method for extending observed or forecast mortality to the oldest ages assumes that mortality rates increase at a linearly decreasing rate up to some target age. In an examination of the fit of 11 functions at ages 80 to 110 , Boleslawki \& Tabeau (2001) found the CoaleKisker method to be superior when reliable data are available to at least age 90 , but they recommended polynomial extrapolation when reliable data are available only to age 85 . Buettner \& Zlotnik (2005) found the logistic model, which does not require specification of an upper limit, less restrictive and therefore preferable to Coale-Kisker for very-long-term forecasts. An alternative approach is the relational model developed by Himes et al. (1994), which extends observed mortality to age 99 by means of a linear relational model based on the logit transformation of $m_{x}$ from age 45; this method also makes no assumption about the upper limit. The Coale \& Guo (1989) method, which does use a target, was supported by modelling by Renshaw \& Haberman (2003b).

\section{The Estimation of UnCERTAinty}

While the point forecast of mortality is of primary interest, it is also important to provide an indication of the likely range of future values. Traditionally, this has been addressed through scenarios, whereby high and low scenarios provide the range around the medium scenario (or forecast). This subjective approach has several inadequacies (Lee \& Tuljapurkar, 1994; Booth, 2004), notably that it is not possible to specify the probability of the 
high-low range. More recent methods estimate the uncertainty of the forecast so as to provide probabilistic prediction intervals.

Estimating the uncertainty of a point forecast of an age-specific mortality rate or of life expectancy is a subject of ongoing research (e.g. Lutz \& Goldstein, 2004). Three broad approaches have been employed: model-based ex-ante error estimation; expert-based ex-ante error estimation; and ex-post error estimation. The estimate will vary depending on the method used and on the extent to which the various sources of error are taken into account. In addition, in estimating the uncertainty of measures which aggregate or average individual forecast quantities, it is necessary to take account of relevant correlations among individual forecast errors. These issues are discussed in this section.

\subsection{Sources of Error}

There are many sources of error in forecasting demographic rates. Alho (1990) classified error into four different, but related, sources: model misspecification, parameter estimation, errors in informed judgement and inherent random variation (see also Keilman, 1990). The first, model misspecification, may occur with respect to the assumed underlying model of the data (e.g. a parameterisation function) or the forecasting model (e.g. a time series model) or both. The variances and covariances of parameter estimates (the second source of error) are derived either by standard estimation or by bootstrapping - resampling from the original data to create replicate datasets from which the variances and covariances can be estimated. Regarding the third source, informed judgement in statistical modelling refers to 'prior' beliefs about model parameters and the weight given to them in forecasting (Alho, 1992); see also Alho (2005). With respect to the last source, observed deaths have often been regarded as being subject to Poisson variability (Brillinger, 1986), though this may understate the true variance. GLM approaches often employ the over-dispersed Poisson (Renshaw \& Haberman, 2003b; Renshaw \& Haberman, 2006), while Li et al. (forthcoming) use the negative binomial to take account of individual heterogeneity. In addition to this random variation, the data are subject to non-random measurement error, including age mis-statement and omissions (Stoto, 1988).

Ideally, all sources of error should be taken into account when presenting prediction intervals for forecasts. Prediction intervals which omit one or more sources of uncertainty will give a misleading impression of confidence in the forecast. Estimates of uncertainty based only on time series parameter uncertainty will be overly narrow, particularly when the model is highly structured, such as Lee-Carter with a random walk with drift forecast. Cairns (2000) notes that parameter uncertainty and errors due to model misspecification are relatively neglected in actuarial science. 


\subsection{Correlations among Forecast Errors}

Three types of correlation among forecast errors may be relevant in estimating uncertainty in mortality forecasting. These are temporal or serial correlation, correlation across age, and correlation between subpopulations. These correlations affect the extent to which (positive and negative) errors cancel in averaging or aggregation; the stronger the positive correlation, the lesser the degree of cancellation and the wider the prediction interval of the aggregate measure (Lee, 1999). Correlations among errors are taken into account in the forecast either analytically (Lee \& Tuljapurkar, 2000) or, more commonly, through simulation. When the latter is used, all sources of error can be taken into account and appropriately combined.

It is to be expected that forecast, age-specific death rates are positively correlated over time; Lee \& Tuljapurkar (2000) noted very high autocorrelation in rates of change. Life expectancy is similarly correlated. Time series methods, which take autocorrelation into account by specifically modelling the relationship between time-dependent parameters in successive years, thus tend to produce wide prediction intervals. Time series approaches permit the simulation of individual sample paths, which may then be used as input in a more complex stochastic model which includes other sources of error. Note that regression-based methods are generally not useful in generating future sample paths.

Positive correlations across age arise from the regularity of modelled age patterns, and because the conditions resulting in high or low annual mortality rates often apply over the whole age range or a broad age group. High positive correlations result in wider prediction intervals for measures which aggregate or average across age, such as life expectancy. Alho (1998) found correlations of about 0.95 between neighbouring ages for mortality rates. Lee \& Tuljapurkar (2000) and others have concluded that perfect correlation can be assumed, resulting in some overestimation of the prediction interval.

In certain circumstances, it is necessary to take correlations among subpopulations into account; for example, in combining subpopulation mortality forecasts. Cross-national correlations cannot be ignored in European forecasts (Alho et al., 2006). Cross-national correlations can be handled by post-processing the forecast results (see Alho \& Spencer, 2005, p292). Positive correlations between the sexes also arise; the common assumption of perfect correlation results in some overestimation of population forecast uncertainty (Keilman et al., 2002).

\subsection{Model-Based ex-ante Error Estimation}

Statistical models provide a basis for estimating error from the different sources. This section first discusses error estimation in relation to the two

${ }^{8}$ Denton et al. (2005) also demonstrate a model-free non-parametric method based on bootstrap procedures, and a partially parametric method based on the autoregressive bootstrap. 
main extrapolative methods: Lee-Carter and GLM. These models allow the estimation of parameter uncertainty and random error, but do not cover errors arising from model misspecification and informed judgement. These additional sources of error can be specifically modelled in a more comprehensive framework, as discussed below.

In Lee-Carter and related time series approaches, forecast uncertainty arises from both the underlying and time series models. In estimating uncertainty, Lee \& Carter (1992) included only uncertainty in the extrapolation, because this usually dominates in the long term. Booth et al. (2002) additionally took error in the estimation of $d$ into account; this increased the standard error of a one-year forecast of by less than $2 \%$, but of a 51 -year forecast by $25 \%$ to $63 \%$ depending on the length of the fitting period.

The accurate estimation of forecast intervals for Lee-Carter and related methods has been the subject of recent research. Methods incorporating all sources of parameter uncertainty have been developed in the context of the Poisson log-bilinear model by Koissi et al. (2006) using residual (nonparametric) bootstrapping, by Brouhns et al. (2005) using parametric bootstrapping and by Li et al. (forthcoming) using parametric bootstrapping together with a relaxation of the Lee-Carter structure to allow for individual heterogeneity in each age-period cell. Koissi \& Shapiro (2006) used a fuzzy model formulation. Pedroza (2006) used a state space framework combined with Bayesian estimation to produce forecast prediction intervals that incorporate all sources of error.

When GLM approaches are employed, estimates are provided of the variances and covariances of parameter estimates and, indirectly, the inherent random variation. From these, the uncertainty of forecasts can be derived, either analytically or by simulation, in the form of the distribution of the forecast for each year. Percentiles can be used to determine prediction intervals. These derived distributions can be used in more complex models which include other sources of error. As autocorrelation is not specifically modelled, individual sample paths are not generated.

A different model-based approach is to model forecast errors per se. Alho $\&$ Spencer (1985) employed a parametric model of the main sources of error to construct prediction intervals for short-term horizons: the model includes model misspecification, informed judgement and parameter estimation. Estimates of uncertainty based on historical naïve forecasts provide a conservative baseline for the assessment of forecast errors. Alho $(1998,2003)$ related errors produced by historical naïve forecasts for Finland to forecast length, and used this to inform prediction intervals for new Finnish forecasts. Where historical data are not available for a population, information on the variance and autocorrelation of errors may be borrowed from another suitable population. This approach is discussed in detail in Alho \& Spencer (2005). 
Cairns (2000) used the Bayesian paradigm to develop a coherent approach to the estimation of all sources of uncertainty. Estimating uncertainty due to model misspecification requires knowledge of the universe of possible models and the numerical specification of the associated probabilities; a more feasible approach is to use sensitivity testing to gauge the impact of model choice on the final forecast (Continuous Mortality Investigation Bureau, 2004).

\subsection{Expert-Based ex-ante Error Estimation}

When the target point forecast is based on the expectations of a group of experts, uncertainty may be specified in the form of expert expectations about target high and low bounds, corresponding to a particular probability prediction interval. The averages for each bound are then assumed to correspond to the specified prediction interval of a normal distribution (Lutz et al., 1996b, 1997; Lutz \& Scherbov, 1998), thereby providing an estimate of the standard error. The method has been shown to be robust to changes in both the probability and distributional form (Lutz \& Scherbov, 1998; Lutz et al., 1999). It has been questioned, however, whether experts consider the bounds of annual point forecasts or of temporal averages and whether they are able to specify values representing probability bounds with reasonable accuracy (Lee, 1999, p187).

In applications, the sample path for mortality is chosen on the basis of a random number which determines the percentile of the target distribution; assuming temporal linearity, this percentile defines the sample path, implying perfect autocorrelation. The method is not suited to short-term forecasting where variation may be greater than can be captured by the combined assumptions of linearity and normality (Lutz et al., 1996b); Alders \& De Beer (1998, cited in De Beer \& Alders, 1999, p4) show that this problem is also not negligible in the longer term. The assumption of linearity and perfect autocorrelation was later relaxed by the addition of a random term (Lutz et al., 1999, 2001). Criticism that expert expectation is overconfident and produces overly narrow prediction intervals, particularly when the recent trend is unchanging (Keilman, 1990), contributed to a greater emphasis on expert argument rather than opinion (Lutz et al., 2004). Lutz et al. (1996a) argue that the expert-based approach is the only meaningful way to capture future uncertainty.

Expert expectation has also been used by Alders \& De Beer (2005) to specify the uncertainty of a mortality forecast derived from a deterministic model. Their approach, which is described as 'argument-based forecasting' (Alders \& De Beer, 2005, p57), involved the use of judgement based on four considerations: smoking trends by sex; possibilities for mortality decline at young ages; ongoing rectangularisation of the survival curve; and the role of medical advances. 


\subsection{Ex-Post Error Estimation}

The third approach to the estimation of uncertainty involves the use of empirical errors in past forecasts to estimate the variability in future forecasts. It is assumed that the future will not differ from the past and that errors are normally distributed or can be modelled. Uncertainty over the forecast period is derived from the overall estimate of the variance according to the estimated (or assumed) degree of autocorrelation. The variance may be specified for the last year of the forecast, for example as a target prediction interval, and interpolation achieved for the intervening years by assuming a random walk model. Alternatively extrapolative forecasts of ex-post errors may be made (e.g. De Beer, 1997). Perfect correlation across age is generally assumed.

Ex-post errors are used to derive prediction intervals for a separatelyderived (deterministic) forecast, with which they should be consistent (Van Hoorn \& De Beer, 2001). The approach is advantageous where a subjective point forecast is preferred, for example because of recent structural change. However, it should be noted that ex-post errors for periods of structural change may not be relevant for future forecasts (De Beer \& Alders, 1999).

Detailed studies of errors in official mortality forecasts have used multivariate methods to separate out the effects of length of forecast horizon, the difficulty of the particular period and the base year (Keilman, 1990; De Beer, 1997; Keilman, 1997). Additional effects include the interaction between difficulty and forecast method, the role of luck and the reasoning behind the choice of method, and the causes of forecast error (for example, model misspecification or an actual change in trend) (De Beer, 2000). Bias towards older forecasts, because of longer error series, must also be taken into account. Keilman $(1990,1997)$ found no clear evidence of improvement over time in forecasting mortality rates.

\section{Conclusions}

The above discussion of methods has been organised into three approaches: expectation, extrapolation and explanation. Most developments have taken place in the extrapolative approach. Expectations are generally not a good basis for mortality forecasting, either at the individual or population level. Individual expectations are relevant only to the very-shortterm future and have limited applicability. At the population level, the conservativeness of expert-opinion-based targets has been a persistent source of inaccuracy, while the validity of forecasts and their uncertainty based on the expectations of a group of experts has been shown to be open to question and has yet to be fully evaluated.

Explanation has received relatively little attention: this approach is not useful for overall mortality forecasting and demands decomposition by cause 
of death. Willekens (1990) noted that the explanatory approach is the ideal and hence the eventual goal in the development of demographic forecasting. In the case of mortality, this goal would appear to be distant. At present, causal modelling is limited to the relatively few causes of death for which the determinants are well understood; for example, lung cancer modelling is based on lagged smoking prevalence rates. ${ }^{9}$ Even where determinants are well understood and measurable, causal models are not widely used because of a lack of sufficient data on the determinants, either for forecasting or for using as lagged variables. Should well-defined explanatory models become available for most or all causes of death, it would still not be possible to forecast overall mortality simply as the sum of the independent forecasts; rather, comorbidities and dependencies among causes would need to be taken into account. ${ }^{10}$ The complexity of such models renders this approach unlikely to fully inform forecasting for many decades to come. Furthermore, the difficulty (at current levels of knowledge) in identifying cause of death at the advanced (and increasing) ages at which most deaths occur severely limits the usefulness of the explanatory approach, and indeed any approach involving decomposition by cause of death.

Within the extrapolative approach, most recent developments have focused on two and three-factor underlying models. Zero-factor models of aggregate measures, notably life expectancy, provide no information about changes in the age pattern, and the independent forecasting of age-specific rates may produce irregular and implausible age patterns. The one-factor parameterisation functions used in mortality graduation are also inadequate; though they have the advantage of smoothness across age, they present serious problems for forecasting, including parameter uninterpretability and over-parameterisation, necessitating multivariate time series models to avoid implausible trends and forecast age patterns. The one-factor shifting logistic appears to avoid these problems.

Two-factor models incorporate time (equivalent to age in age-cohort models) which, being fundamental to forecasting, is a major advantage. Methods using principal components techniques have proved to be successful. The Lee-Carter method, involving a single time-varying parameter, generally produces plausible forecast trends and permits a changing age pattern of mortality, though the fixed age pattern of change may lead to implausible age patterns in the longer term. Recent related advances incorporate acrossage smoothness, improve estimation and offer possible enhancements in forecast accuracy. GLM methods, including dynamic parameterisations, have been less successful in forecasting because nonlinearities in time can

\footnotetext{
${ }^{9}$ Even here, the accepted model has limited applicability: different patterns of change have been found in Japan, for example (Continuous Mortality Investigation Bureau, 2004).

${ }^{10}$ Alternatively, multistate models can be used, based on observed transition rates.
} 
lead to implausible forecast trends. The $p$-spline regression model appears to have been successful in applications to date.

Three-factor models have the additional advantage of incorporating cohort effects, but in practice often suffer from data unavailability and difficulties in forecasting cohort trends. The Lee-Carter APC method appears promising, but has yet to be comprehensively assessed. Ways of incorporating cohort effects have been reviewed and tested by the U.K. Actuarial Profession (Government Actuary's Department, 2001; Continuous Mortality Investigation Bureau, 2002, 2004, 2005, 2006, 2007) in response to the observation of clear cohort patterns.

For any forecast, accuracy is a main goal. However, relatively little is known about the performance of different forecasting methods. While interest in the accuracy of forecasts has increased, the main focus has been the ex-post estimation of the uncertainty of current forecasts rather than the relative performance of a particular method. Findings that forecast accuracy depends on the particular circumstances of the period or population (Murphy, 1990; Keyfitz, 1991; Murphy, 1995; Keilman, 1997; Booth et al., 2005) do not inform method choice. Existing comparative evaluations of forecast accuracy (Booth et al., 2005; Booth et al., 2006) are limited to a single forecast jump-off date, and more extensive evaluations are required.

The correct estimation of forecast uncertainty is also an important goal. Statistical methods, including bootstrapping and simulation, have been increasingly applied to incorporate different sources of forecast error and to improve their estimation. The quantification of uncertainty due to model misspecification remains a more difficult task and an important area for future research. Actuarial applications have highlighted the importance of allowing for all sources of uncertainty in estimating life insurance and pension liabilities (e.g. Olivieri, 2001; Pitacco, 2004).

Forecasting knowledge has been substantially increased in recent decades through the high level of research activity and ensuing debates. This has been assisted by improved access to high-quality data through the construction of databases (e.g. the Human Mortality Database, http://www.mortality.org/) and the development of specialised mortality forecasting software using $\mathrm{R}$ as the common programming language. Hyndman, Booth, Tickle and Maindonald have developed and made available an $\mathrm{R}$ software package which includes modelling and forecasting using Lee-Carter and its variants and Hyndman-Ullah (http://www.robjhyndman.com). The CMIB has also developed illustrative software to fit the $p$-spline and Lee-Carter models and to generate scenarios based on them; this is available as an Excel add-in based on $\mathrm{R}$ programming (http://www.actuaries.org.uk/knowledge/ $\mathrm{cmi} / \mathrm{cmi}_{-} w \mathrm{p} /$ tables_software). The potential for future progress in mortality forecasting is significantly enhanced by the accessibility of these tools.

Substantial progress has been made since 1980 in developing new 
methods for forecasting mortality. A significant challenge ahead is to evaluate these existing methods in a wide variety of settings through comparative research, focussing on both the accuracy of the point forecast and its uncertainty. It must be noted that research in mortality forecasting has benefited from the relative stability of the mortality process and its rates of change. An examination of the effects of instability on forecast performance is thus necessary in order to completely evaluate the methods.

In conclusion, mortality forecasting has gained in importance in recent decades at a time when life expectancy has increased with unexpected rapidity and exceeded previously-held limits (Oeppen \& Vaupel, 2002). Such increases have provided the impetus for the improvement of mortality forecasting methods. This challenge has been addressed by demographers, statisticians and actuaries, if rather belatedly by official agencies and the actuarial profession. In the face of continuing increases in life expectancy, use of the best available methods is now imperative, particularly by actuaries practising in the insurance and financial risk industry where the ramifications of inaccurate forecasting are acute.

\section{ACKNOWLEDGEMENTS}

Thanks to Piet de Jong and an anonymous reviewer for helpful comments and Vanessa Frame for bibliographical support.

\section{REFERENCES}

Ahlburg, D.A. (1995). Simple versus complex models: evaluation, accuracy, and combining. Mathematical Population Studies, 5(3), 281-290.

Ahlburg, D.A. \& VAupel, J.W. (1990). Alternative projections of the U.S. population. Demography, 27(4), 639-652.

Alders, M. \& De BeER, J. (2005). An expert knowledge approach to stochastic mortality forecasting in the Netherlands. In (N. KeILman, ed.) Perspectives on mortality forecasting (Vol. II. Probabilistic models, pp39-64). Swedish Social Insurance Agency, Stockholm.

Alderson, M. \& Ashwood, F. (1985). Projection of mortality rates for the elderly. Population Trends, 42, 22-29.

Alro, J.M. (1990). Stochastic methods in population forecasting. International Journal of Forecasting, 6(4), 521-530.

Alho, J.M. (1991). Effect of aggregation on the estimation of trend mortality. Mathematical Population Studies, 2, 53-67.

Alho, J.M. (1992). Estimating the strength of expert judgement: the case of U.S. mortality forecasts. Journal of Forecasting, 11, 157-167.

Alho, J.M. (1998). A stochastic forecast of the population of Finland (Reviews No. 1998/4). Statistics Finland, Helsinki.

Alho, J.M. (2003). Experiences from forecasting mortality in Finland. In (T. Bengtsson \& N. Keilman, eds.) Perspectives on mortality forecasting (Vol. I. Current practice, 29-40). Swedish Social Insurance Agency, Stockholm. 
Alho, J.M. (2005). Remarks on the use of probabilities in demography and forecasting. In (N. KeIlman, ed.) Perspectives on mortality forecasting (Vol. II. Probabilistic models, 27-38). Swedish Social Insurance Agency, Stockholm.

Alho, J.M. \& Spencer, B.D. (1985). Uncertain population forecasting. Journal of the American Statistical Association, 80, 306-314.

Alho, J.M. \& Spencer, B.D. (1990). Error models for official mortality forecasts. Journal of the American Statistical Association, 85(411), 609-616.

Alho, J.M. \& Spencer, B.D. (2005). Statistical Demography and Forecasting. Springer, New York.

Alho, J.M., Alders, M., Cruijsen, H., Keilman, N., Nikander, T. \& Pham, D.Q. (2006). New forecast: population decline postponed in Europe. Statistical Journal for the United Nations Economic Commission for Europe, 23(1), 1-10.

Babel, B., Bomsdorf, E. \& Schmidt, R. (2008). Forecasting German mortality using panel data procedures. Journal of Population Economics, 21(3), 541-555.

BeLL, W. (1997). Comparing and assessing time series methods for forecasting age-specific fertility and mortality rates. Journal of Official Statistics, 13(3), 279-303.

Bell, W.R. \& Monsell, B.C. (1991). Using principal components in time series modeling and forecasting of age-specific mortality rates. Paper presented at the American Statistical Association 1991 Proceedings of the Social Statistics Section.

Bengtsson, T. \& Keilman, N. (eds.) (2003). Perspectives on mortality forecasting (Vol. I. Current practice). Swedish National Social Insurance Board, Stockholm.

Benjamin, B. \& Pollard, J.H. (1980). The analysis of mortality and other actuarial statistics. Heinemann, London.

Board of Trustees of the Federal Old-Age and Survivors Insurance and Disability InSURANCE TRust Funds (2004). Annual report. Washington DC.

Boleslawski, L. \& Tabeau, E. (2001). Comparing theoretical age patterns of mortality beyond the age of 80. In (E. Tabeau, A. Van Den Berg Jeths \& C. Heathcote, eds.) Forecasting mortality in developed countries: insights from a statistical, demographic and epidemiological perspective (127-155). Kluwer Academic Publishers, Dordrecht.

BongaARTS, J. (2005). Long-range trends in adult mortality: models and projection methods. Demography, 42(1), 23-49.

Bongants, J. (2006). How long will we live? Population and Development Review, 32(4), 605628.

Bongatits, J. \& Feeney, G. (2002). How long do we live? Population and Development Review, 28(1), 13-29.

Bongatits, J. \& Feeney, G. (2003). Estimating mean lifetime. Proceedings of the National Academy of Sciences, 100(23), 13127-13133.

BongaArts, J. \& Feeney, G. (2006). The quantum and tempo of life-cycle events. Vienna Yearbook of Population Research 2006, 115-151.

Воотн, H. (2004). On the importance of being uncertain: forecasting population futures for Australia. People and Place, 12(2), 1-12.

Bоотн, H. (2006). Demographic forecasting: 1980 to 2005 in review. International Journal of Forecasting, 22, 547-581.

Bоoth, H. \& Tickle, L. (2003). The future aged: new projections of Australia's elderly population. Australasian Journal on Ageing, 22(4), 196-202.

Boотн, H. \& Tickle, L. (2004). Beyond three score years and ten: prospects for longevity in Australia. People and Place, 12(1), 15-27.

Booth, H., Maindonald, J. \& Sмith, L. (2001). Age-time interactions in mortality projection: applying Lee-Carter to Australia (Working Papers in Demography No. 85). Australian National University, Canberra.

Booth, H., Maindonald, J. \& Smith, L. (2002). Applying Lee-Carter under conditions of variable mortality decline. Population Studies, 56(3), 325-336. 
Boотh, H., Tickle, L. \& Smith, L. (2005). Evaluation of the variants of the Lee-Carter method of forecasting mortality: a multi-country comparison. In (A. Dharmalingam \& I. Pool, eds.) New Zealand Population Review, Special Issue on Stochastic Population Projections, 31(1), 13-37.

Booth, H., Hyndman, R.J., Tickle, L. \& De Jong, P. (2006). Lee-Carter mortality forecasting: a multi-country comparison of variants and extensions. Demographic Research, 15(9), 289-310.

Box, G., Jenkins, G.M. \& Reinsel, G.C. (1994). Time series analysis: forecasting and control (3rd ed.). Prentice Hall, Englewood, NJ.

Brass, W. (1971). On the scale of mortality. In (W. Brass, ed.) Biological aspects of demography (69-110). Taylor and Francis, London.

Brass, W. (1974). Perspectives in population prediction: illustrated by the statistics of England and Wales. Journal of the Royal Statistical Society, Series A, 137(4), 532-583.

Brillinger, D.R. (1986). The natural variability of vital rates and associated statistics. Biometrics, 42(December), 693-734.

Brouhns, N., Denuit, M. \& Vermunt, J.K. (2002). A Poisson log-bilinear regression approach to the construction of projected life-tables. Insurance: Mathematics and Economics, 31, 373-393.

Brouhns, N., Denuit, M. \& Van Keilegom, I. (2005). Bootstrapping the Poisson log-bilinear model for mortality forecasting. Scandinavian Actuarial Journal, 3, 212-224.

Buettner, T. \& Zlotnik, H. (2005). Prospects for increasing longevity as assessed by the United Nations. Genus, LXI(1), 213-233.

CaIrns, A.J.G. (2000). A discussion of parameter and model uncertainty in insurance. Insurance: Mathematics and Economics, 27, 313-330.

CARrière, J.F. (1992). Parametric models for life tables. Transactions of the Society of Actuaries, 44, 77-99.

Carter, L.R. \& Prskawetz, A. (2001). Examining structural shifts in mortality using the Lee-Carter method (MPIDR Working Paper No. WP 2001-007). Max Planck Institute for Demographic Research.

Caselli, G. (1996). Future longevity among the elderly. In (G. Caselli \& A. Lopez, eds.) Health and mortality among elderly populations. Clarendon Press, Oxford.

Coale, A.J. \& McNeil, D.R. (1972). The distribution by age of the frequency of first marriage in a female cohort. Journal of the American Statistical Association, 67(340), 743749.

Conle, A.J. \& Guo, G. (1989). Revised regional model life tables at very low levels of mortality. Population Index, 55(4), 613-643.

CoAle, A.J. \& Kisker, E.E. (1990). Defects in data on old-age mortality in the United States: new procedures for calculating schedules and life tables at the highest ages. Asian and Pacific Population Forum, 4(1), 1-31.

Congdon, P. (1993). Statistical graduation in local demographic analysis and projection. Journal of the Royal Statistical Society, 156(2), 237-270.

Continuous Mortality Investigation Bureau (1990). Standard tables of mortality based on the 1979-1982 experiences, CMI report no. 10. London: Institute of Actuaries and Faculty of Actuaries.

Continuous Mortality Investigation Bureau (1999). Standard tables of mortality based on the 1991-1994 experiences, CMI report no. 17. London: Institute of Actuaries and Faculty of Actuaries.

Continuous Mortality Investigation Bureau (2002). An interim basis for adjusting the "92" series mortality projections for cohort effects, CMI Working paper no. 1. London: Institute of Actuaries and Faculty of Actuaries.

Continuous Mortality Investigation Bureau (2004). Projecting future mortality: a discussion paper, CMI Working paper no. 3. London: Institute of Actuaries and Faculty of Actuaries. 
Continuous Mortality Investigation Bureau (2005). Projecting future mortality: towards a proposal for a stochastic methodology, CMI Working paper no. 15. London: Institute of Actuaries and Faculty of Actuaries.

Continuous Mortality Investigation Bureau (2006). Stochastic projection methodologies: further progress and $p$-spline model features, example results and implications, CMI Working paper no. 20. London: Institute of Actuaries and Faculty of Actuaries.

Continuous Mortality Investigation Bureau (2007). Stochastic projection methodologies: Lee-Carter model features, example results and implications, CMI Working paper no. 25. London: Institute of Actuaries and Faculty of Actuaries.

Crimmins, E.M. (1981). The changing pattern of American mortality decline, 1947-1977, and its implication for the future. Population and Development Review, 7(2), 229-254.

Currie, D., Durban, M. \& Eilers, P.H.C. (2004). Smoothing and forecasting mortality rates. Statistical Modelling, 4, 279-298.

Czado, C., Delwarde, A. \& Denuit, M. (2005). Bayesian Poisson logbilinear mortality projections. Insurance: Mathematics and Economics, 36, 260-284.

De BeER, J. (1989). Projecting age-specific fertility rates by using time-series methods. European Journal of Population, 5(1989), 315-346.

De BEeR, J. (1997). The effect of uncertainty of migration on national population forecasts: the case of the Netherlands. Journal of Official Statistics, 13(3), 227-243.

De BeEr, J. (2000). Dealing with uncertainty in population forecasting. Statistics Netherlands, Department of Population, Voorburg.

De Beer, J. \& Alders, M. (1999). Probabilistic population and household forecasts for the Netherlands. Working paper no. 45. Paper presented at the Joint ECE-Eurostat Work Session on Demographic Projections, 3-7 May 1999, Perugia, Italy.

De Jong, P. \& Tickle, L. (2006). Extending Lee-Carter mortality forecasting Mathematical Population Studies, 13(1), 1-18.

De Jong, P. \& Marshall, C. (2007). Forecasting mortality using the Wang transform. ASTIN Bulletin, 37(1), 149-162.

Denton, F., Feaver, C. \& Spencer, B. (2005). Time series analysis and stochastic forecasting: an econometric study of mortality and life expectancy. Journal of Population Economics, 18(2), 203-227.

Ewbank, D.C., Gómez de León, J.C. \& Stoto, M.A. (1983). A reducible four-parameter system of model life tables. Population Studies, 37(1), 105-127.

Forfar, D.O. (2004). Mortality laws. In (J.L. Teugels \& B. Sundt, eds.) Encyclopedia of actuarial science (1139-1145). Wiley, West Sussex.

Forfar, D.O. \& Smith, D.M. (1987). The changing shape of English life tables. Transactions of the Faculty of Actuaries, 40, 98-134.

Forfar, D.O., McCutcheon, J.J. \& Wilkie, A.D. (1988). On graduation by mathematical formula. Journal of the Institute of Actuaries, 115(1), 97-245.

Gage, T.B. \& Mode, C.J. (1993). Some laws of mortality: how well do they fit? Human Biology, 65(3), 445-461.

Girosi, F. \& KIng, G. (2006). Demographic forecasting. Cambridge University Press, Cambridge.

Golulapati, R., De Ravin, J.W. \& Trickett, P.J. (1984). Projections of Australian mortality rates, 1981-2020 (Occasional paper no. 1983/2). Australian Bureau of Statistics.

Goss, S.C., Wade, A., Bell, F. \& Dussault, B. (1998). Historical and projected mortality for Mexico, Canada, and the United States. North American Actuarial Journal, 2(4), 108-128.

Government Actuary's Department (2001). National population projections: review of methodology for projecting mortality. Government Actuary's Department: London.

Government Actuary's Department (2006). National population projections 2004-based. Government Actuary's Department: London.

Guillot, M. (2003). The cross-sectional average length of life (CAL): a period mortality measure that reflects the experience of cohorts. Population Studies, 57(1), 41-54. 
Gutterman, S. \& Vanderhoof, I.T. (1998). Forecasting changes in mortality: a search for a law of causes and effects. North American Actuarial Journal, 2(4), 135-138.

Hannerz, H. (1999). Methodology and applications of a new law of mortality. Department of Statistics, University of Lund, Sweden, Lund.

Hannerz, H. (2001a). Presentation and derivation of a five-parameter survival function intended to model mortality in modern female populations. Scandinavian Actuarial Journal, 2001(2), 176-187.

Hannerz, H. (2001b). Manhood trials and the law of mortality. Demographic Research, 4(Article 7), 185-202.

HANNERZ, H. (2001c). An extension of relational methods in mortality estimation. Demographic Research, 4(Article 10), 337-367.

Hartmann, M. (1987). Past and recent attempts to model mortality at all ages. Journal of Official Statistics, 3(1), 19-36.

Harvey, A. (1989). Forecasting, structural time series models and the Kalman filter. Cambridge University Press, Cambridge.

Hauser, R.M. \& Willis, R.J. (2005). Survey design and methodology in the Health and Retirement Study and the Wisconsin Longitudinal Study. In (L.J. Waite, ed.) Aging, health, and public policy: demographic and economic perspectives. Population council. Supplement to Population and Development Review, 30 (2004), New York.

Heathcote, C. \& Higgins, T. (2001a). A regression model of mortality, with applications to the Netherlands. In (E. Tabeau, A. Van Den Berg Jeths \& C. Heathcote, eds.) Forecasting mortality in developed countries: insights from a statistical, demographic and epidemiological perspective (59-82). Kluwer Academic Publishers, Dordrecht.

Heathcote, C. \& Higgins, T. (2001b). Forecasting mortality from regression models: the case of the Netherlands. In (E. Tabeau, A. Van Den Berg Jeths \& C. Heathcote, eds.) Forecasting mortality in developed countries: insights from a statistical, demographic and epidemiological perspective (83-103). Kluwer Academic Publishers, Dordrecht.

Heligman, L. \& Pollard, J.H. (1980). The age pattern of mortality. Journal of the Institute of Actuaries, 107(1, No 434), 49-80.

Himes, C.L., Preston, S.H. \& Condran, G.A. (1994). A relational model of mortality at older ages in low mortality countries. Population Studies, 48, 269-291.

Hollmann, F.W., Mulder, T.J. \& Kallan, J.E. (2000). Methodology and assumptions for the population projections of the United States: 1999 to 2100. Working paper 38, Population Division, U.S. Bureau of the Census.

Hyndman, R.J. \& Ullah, S. (2007). Robust forecasting of mortality and fertility rates: a functional data approach. Computational Statistics and Data Analysis, 51, 4942-4956.

IDLER, E.L. \& BenYAminI, Y. (1997). Self-rated health and mortality: a review of twenty-seven community studies. Journal of Health and Social Behavior, 38(1), 21-37.

Kannisto, V. (1994). Development of oldest-old mortality, 1950-1990: evidence from 28 developed countries. Odense University Press, Odense, Denmark.

Kannisto, V., Lauritsen, J., Thatcher, A.R. \& Vaupel, J.W. (1994). Reductions in mortality at advanced ages: several decades of evidence from 27 countries. Population and Development Review, 20(4), 793-810.

KeIlman, N. (1990). Uncertainty in population forecasting: issues, backgrounds, analyses, recommendations. Swets \& Zeitlinger, Amsterdam.

Keilman, N. (1997). Ex-post errors in official population forecasts in industrialized countries. Journal of Official Statistics, 13(3), 245-277.

Keilman, N. (ed.). (2005). Perspectives on mortality forecasting (Vol. II. Probabilistic models). Swedish Social Insurance Agency, Stockholm.

Keilman, N., Pham, D.Q. \& Hetland, A. (2002). Why population forecasts should be probabilistic - illustrated by the case of Norway. Demographic Research, 6(15), 409-453.

KeyfitZ, N. (1982). Choice of function for mortality analysis: effective forecasting depends on a minimum parameter representation. Theoretical Population Biology, 21(3), 329-352. 
Keyfitz, N. (1991). Experiments in the projection of mortality. Canadian Studies in Population, 18(2), 1-17.

Koissi, M.-C. \& Shapiro, A.F. (2006). Fuzzy formulation of the Lee-Carter model for mortality forecasting. Insurance: Mathematics and Economics, 39, 287-309.

Koissi, M.-C., Shapiro, A.F. \& Hognas, G. (2006). Evaluating and extending the Lee-Carter model for mortality forecasting: bootstrap confidence interval. Insurance: Mathematics and Economics, 38, 1-20.

Kostaki, A. (1988). Contributions to the methodology and application of the Heligman-Pollard formula. University of Lund, Lund.

Kunst, A.E., Mackenbach, J.P., Lautenbach, H., Oei, F.B. \& Bijlsma, F. (2002). Gains in life expectancy by eliminating major causes of death: revised estimates taking into account competing causes of death. In (G. Wunsch, M. Mouchart \& J. Duchene, eds.) The life table: modelling survival and death (191-207). Kluwer Academic Publishers, Dordrecht, The Netherlands.

LE Bras, H. (2005). Mortality tempo versus removal of causes of mortality: opposite views leading to different estimations of life expectancy. Demographic Research, 13(25), 615640.

LEE, R.D. (1992). Stochastic demographic forecasting. International Journal of Forecasting, 8(3), 315-327.

LEE, R.D. (1999). Probabilistic approaches to population forecasting. In (W. LuTZ, J.W. Vaupel \& D.A. Ahlburg, eds.) Frontiers of population forecasting (156-190). Population Council. A supplement to Population and Development Review, 24, 1998, New York.

LEE, R.D. (2000). The Lee-Carter method for forecasting mortality, with various extensions and applications. North American Actuarial Journal, 4(1), 80-93.

LeE, R.D. \& CARTER, L.R. (1992). Modelling and forecasting U.S. mortality. Journal of the American Statistical Association, 87(419), 659-671.

LeE, R.D. \& Tuljapurkar, S. (1994). Stochastic population forecasts for the United States: beyond high, medium, and low. Journal of the American Statistical Association, 89(428), 1175-1189.

Lee, R.D. \& Tuljapurkar, S. (2000). Population forecasting for fiscal planning: issues and innovations. In (A. Auerbach \& R. Lee, eds.) Population and fiscal policy (7-57). Cambridge University Press, Cambridge.

Lee, R.D. \& Miller, T. (2001). Evaluating the performance of the Lee-Carter method for forecasting mortality. Demography, 38(4), 537-549.

LI, S.-H. \& CHAN, W.-S. (2005). Outlier analysis and mortality forecasting: the United Kingdom and Scandinavian countries. Scandinavian Actuarial Journal, 3, 187-211.

LI, S.-H., HARDY, M.R. \& TAN, K.S. (forthcoming). Uncertainty in mortality forecasting: an extension to the classical Lee-Carter approach. ASTIN Bulletin.

LoNG, J.F. (1995). Complexity, accuracy, and utility of official population projections. Mathematical Population Studies, 5(3), 203-216.

Lundstrom, H. \& Qvist, J. (2004). Mortality forecasting and trend shifts: an application of the Lee-Carter model to Swedish mortality data. International Statistical Review, 72(1), $37-50$.

Lutz, W. \& Scherbov, S. (1998). An expert-based framework for probabilistic national population projections: the example of Austria. European Journal of Population, 14(1), $1-17$.

Lutz, W. \& Goldstein, J.R. (eds.) (2004). How to deal with uncertainty in population forecasting?, Reprint of articles appearing in International Statistical Review, 71(2) and 72(1).

Lutz, W., Goldstein, J.R. \& Prinz, C. (1996a). Alternative approaches to population projection. In (W. Lutz, ed.) The future population of the world. What can we assume today? (14-44). Earthscan, London. 
Lutz, W., Sanderson, W. \& Scherbov, S. (1996b). Probabilistic population projections based on expert opinion. In (W. LuTz, ed.) The future population of the world: what can we assume today? (397-428). Earthscan, London.

Lutz, W., Sanderson, W. \& Scherbov, S. (1997). Doubling of world population unlikely. Nature, 387, 803-805.

Lutz, W., Sanderson, W. \& Scherbov, S. (1999). Expert-based probabilistic population projections. In (W. Lutz, J.W. VAupel \& D.A. Ahlburg, eds.) Frontiers of population forecasting (139-155). Population Council. A Supplement to Population and Development Review, 24 (1998), New York.

Lutz, W., Sanderson, W. \& Scherbov, S. (2001). The end of world population growth. Nature, 412, 543-545.

Lutz, W., SAnderson, W. \& Scherbov, S. (2004). The end of world population growth. In (W. Lutz \& W. SANDERSON, eds.) The end of world population growth in the 21 st century: new challenges for human capital formation and sustainable development. Earthscan, London.

McNown, R. \& Rogers, A. (1989). Forecasting mortality: a parameterized time series approach. Demography, 26(4), 645-660.

McNown, R. \& Rogers, A. (1992). Forecasting cause-specific mortality using time series methods. International Journal of Forecasting, 8(3), 413-432.

McNown, R., Rogers, A. \& Little, J. (1995). Simplicity and complexity in extrapolative population forecasting models. Mathematical Population Studies, 5(3), 235-257.

Manton, K.G., Patrick, C.H. \& Stallard, E. (1980). Mortality model based on delays in progression of chronic diseases: alternative to cause elimination model. Public Health Reports, 95(6), 580-588.

Manton, K.G., Stallard, E. \& Tolley, H.D. (1991). Limits to human life expectancy: evidence, prospects, and implications. Population and Development Review, 17(4), 603-637.

Manton, K.G., Stallard, E. \& Singer, B. (1992). Projecting the future size and health status of the U.S. elderly population. International Journal of Forecasting, 8(3), 433-458.

Mode, C.J. \& Busby, R.C. (1982). An eight-parameter model of human mortality - the single decrement case. Bulletin of Mathematical Biology, 44(5), 647-659.

Mode, C.J. \& JACOBSON, M.E. (1984). A parametric algorithm for computing model period and cohort human survival functions. International Journal of Biomedical Computing, 15, 341-356.

Murphy, M.J. (1990). Methods of forecasting mortality for population projections. In population projections: trends, methods and uses. Occasional paper 38 (87-102). OPCS, London.

Murphy, M.J. (1995). The prospect of mortality: England and Wales and the United States of America, 1962-1989. British Actuarial Journal, 1, 331-350.

Murray, C. \& Lopez, A. (1997). Global mortality, disability, and the contribution of risk factors: global burden of disease study. The Lancet, 349(9063), 1436-1442.

Oeppen, J. \& Vaupel, J.W. (2002). Broken limits to life expectancy. Science, 296, 1029-1031.

OLIVIERI, A. (2001). Uncertainty in mortality projections: an actuarial perspective. Insurance: Mathematics and Economics, 29, 231-245.

OlshansKy, S.J. (1987). Simultaneous/multiple cause-delay (SIMCAD): an epidemiological approach to projecting mortality. Journal of Gerontology, 42(4), 358-365.

Olshansky, S.J. (1988). On forecasting mortality. The Milbank Quarterly, 66(3), 482-530.

Olshansky, S.J. \& Carnes, B.A. (1997). Ever since Gompertz. Demography, 34(1), 1-15.

Pedroza, C. (2006). A Bayesian forecasting model: predicting U.S. male mortality. Biostatistics, 7(4), 530-550.

Pitacco, E. (2004). Survival models in a dynamic context: a survey. Mathematics and Economics, 35, 279-298.

Pollard, J.H. (1987). Projection of age-specific mortality rates Population Bulletin of the United Nations 21-22, 55-69. 
Pollard, J.H. (1998). Keeping abreast of mortality change. Actuarial and Demography Research Paper Series, No. 002/98.

Pollard, J.H. \& Valkovics, E.J. (1992). The Gompertz distribution and its applications. Genus, 48(3-4), 15-27.

Renshaw, A.E. (1991). Actuarial graduation practice and generalised linear and non-linear models. Journal of the Institute of Actuaries, 118, 295-312.

Renshaw, A.E. \& Haberman, S. (2000). Modelling for mortality reduction factors (Actuarial Research Paper No. 127). Department of Actuarial Science and Statistics, City University, London.

Renshaw, A.E. \& Haberman, S. (2003a). Lee-Carter mortality forecasting with age-specific enhancement. Insurance: Mathematics and Economics, 33, 255-272.

Renshaw, A.E. \& Haberman, S. (2003b). Lee-Carter mortality forecasting: a parallel generalized linear modelling approach for England and Wales mortality projections. Applied Statistics, 51(1), 119-137.

Renshaw, A.E. \& Haberman, S. (2003c). On the forecasting of mortality reduction factors. Insurance: Mathematics and Economics, 32, 379-401.

Renshaw, A.E. \& Haberman, S. (2006). A cohort-based extension of the Lee-Carter model for mortality reduction factors. Insurance: Mathematics and Economics, 38, 556-570.

Renshaw, A.E., Haberman, S. \& Hatzoupoulos, P. (1996). The modelling of recent mortality trends in United Kingdom male assured lives. British Actuarial Journal, 2, 449-477.

Rogers, A. (1992). Heterogeneity and selection in multistate population analysis. Demography, 29(1), 31-38.

Rogers, A. \& Planck, F. (1983). Model: a general program for estimating parameterized model schedules of fertility, mortality, migration, and marital and labor force status transitions. International Institute for Applied Systems Analysis, Laxenburg, Austria.

Rogers, A. \& GARD, K. (1991). Applications of the Heligman/Pollard model mortality schedule. Population Bulletin of the United Nations, 30, 79-105.

Rogers, A. \& Little, J.S. (1994). Parameterizing age patterns of demographic rates with the multiexponential model schedule. Mathematical Population Studies, 4(3), 175-195.

Sanderson, W.C. \& Scherbov, S. (2005). Average remaining lifetimes can increase as human populations age. Nature, $\mathbf{4 3 5}(7043), 811-813$.

Shaw, C. (1994). Accuracy and uncertainty of the national population projections for the United Kingdom. Population Trends, 77, 24-32.

SILER, W. (1983). Parameters of mortality in human populations with widely varying life spans. Statistics in Medicine, 2, 373-380.

Sithole, T.Z., Haberman, S. \& Verrall, R.J. (2000). An investigation into parametric models for mortality projections, with applications to immediate annuitants' and life office pensioners' data. Insurance: Mathematics and Economics, 27, 285-312.

Sтото, M.A. (1988). Dealing with uncertainty: statistics for an aging population. The American Statistician, 42(2), 103-110.

Sтото, M.A. \& Durch, J.S. (1993). Forecasting survival, health, and disability: report on a workshop. Population Development and Review, 19(3), 557-581.

TABEAU, E. (2001). A review of demographic forecasting models for mortality. In (E. TABEAU, A. Van Den Berg Jeths \& C. Heathcote, eds.) Forecasting mortality in developed countries: insights from a statistical, demographic and epidemiological perspective (1-32). Kluwer Academic Publishers, Dordrecht.

Tabeau, E., Van Den Berg Jeths, A. \& Heathcote, C. (eds.) (2001a). Forecasting mortality in developed countries: insights from a statistical, demographic and epidemiological perspective. Kluwer Academic Publishers, Dordrecht.

Tabeau, E., Willekens, F. \& van Poppel, F. (2002). Parameterisation as a tool in analysing age, period and cohort effects on mortality: a case study of the Netherlands. In (G. Wunsch, M. Mouchart \& J. Duchene, eds.) The life table: modelling survival and death (141-169). Kluwer Academic Publishers, Dordrecht. 
Tabeau, E., Ekamper, P., Huisman, C. \& Bosch, A. (2001b). Predicting mortality from period, cohort or cause-specific trends: a study of four European countries. In (E. Tabeau, A. Van Den Berg Jeths \& C. Heathcote, eds.) Forecasting mortality in developed countries: insights from a statistical, demographic and epidemiological perspective (159-187). Kluwer Academic Publishers, Dordrecht.

Thatcher, A., Kannisto, V. \& Vaupel, J. (1998). The force of mortality at ages 80 to 120 . In Odense Monographs on Population Aging 5. Odense University Press, Odense, Denmark.

Thatcher, A.R. (1999). The long-term pattern of adult mortality and the highest attained age. Journal of the Royal Statistical Society, Series A, Statistics in Society, 162(1), 5-43.

TulJapurkar, S. (1998). Forecasting mortality change: questions and assumptions. North American Actuarial Journal, 2(4), 127-134.

Tuljapurkar, S. \& Boe, C. (1998). Mortality change and forecasting: how much and how little do we know? North American Actuarial Journal, 2(4), 13-47.

Tuljapurkar, S., Li, N. \& Boe, C. (2000). A universal pattern of mortality decline in the G7 countries. Nature, 405, 789-792.

United Nations (2004). World population to 2300. United Nations, New York.

Van Den Berg Jeths, A., Hoogenveen, R., De Hollander, G. \& Tabeau, E. (2001). A review of epidemiological approaches to forecasting mortality and morbidity. In (E. Tabeau, A. Van Den Berg Jeths \& C. Heathcote, eds.) Forecasting mortality in developed countries: insights from a statistical, demographic and epidemiological perspective (33-56). Kluwer Academic Publishers, Dordrecht.

Van Genugten, M., Hoogenveen, R. \& De Hollander, A. (2001). Incorporating risk factor epidemiology in mortality projections. In (E. TABEAU, A. VAN DEN BERG JeThS \& C. Нелtнсоте, eds.) Forecasting mortality in developed countries: insights from a statistical, demographic and epidemiological perspective (189-204). Kluwer Academic Publishers, Dordrecht.

Van Hoorn, W. \& De Beer, J. (2001). Projecting mortality in population forecasts in the Netherlands. In (E. Tabeau, A. Van Den Berg Jeths \& C. Heathcote, eds.) Forecasting mortality in developed countries: insights from a statistical, demographic and epidemiological perspective (205-226). Kluwer Academic Publishers, Dordrecht.

VAupel, J.W. \& Yashin, A.I. (1985). Heterogeneity's ruses: some surprising effects of selection on population dynamics. The American Statistician, 39(3), 176-185.

Waldron, H. (2005). Literature review of long-term mortality projections. Social Security Bulletin, 66(1), 16-30.

WANG, S.S. (2000). A class of distortion operators for pricing financial and insurance risks. The Journal of Risk and Insurance, 67(2), 15-36.

White, K.M. (2002). Longevity advanced in high-income countries, 1955-96. Population and Development Review, 28(1), 59-76.

Willekens, F.J. (1990). Demographic forecasting; state-of-the-art and research needs. In (C.A. HAZeu \& G.A.B. Frinking, eds.) Emerging issues in demographic research (9-75). Elsevier Science.

Willekens, F.J. \& Baydar, N. (1986). Age-period-cohort models for forecasting fertility (No. 45). NIDI, The Hague.

Willets, R.C. (2004). The cohort effect: insights and explanations. British Actuarial Journal, 10, 833-877.

Willets, R.C., Gallop, A.P., Leandro, P.A., Lu, J.L.C., Macdonald, A.S., Miller, K.A., Richards, S.J., Robjohns, N., Ryan, J.P. \& Waters, H.R. (2004). Longevity in the 21 st century. British Actuarial Journal, 10, 685-898.

Wilmoth, J.R. (1990). Variation in vital rates by age, period and cohort. Sociological Methodology, 20, 295-335.

Wilmoth, J.R. (1993). Computational methods for fitting and extrapolating the Lee-Carter model of mortality change (Technical report). Department of Demography, University of California, Berkeley. 
Wilmoth, J.R. (1995). Are mortality projections always more pessimistic when disaggregated by cause of death? Mathematical Population Studies, 5(4), 293-319.

Wilmoth, J.R. (1996). Mortality projections for Japan: a comparison of four methods. In (G. CASElli \& A. Lopez, eds.) Health and mortality among elderly populations (266-287). Oxford University Press, New York.

Wilmoth, J.R. (2005). Some methodological issues in mortality projection, based on an analysis of the U.S. social security system. Genus, LXI(1), 179-212.

Wolf, D.A. (2004). Another variation on the Lee-Carter model. Paper presented at the Annual meeting of the Population Association of America, Boston.

Wong-Fupuy, C. \& Haberman, S. (2004). Projecting mortality trends: recent developments in the United Kingdom and the United States. North American Actuarial Journal, 8(2), 56-83.

Zaba, B. (1979). The four-parameter logit life table system. Population Studies, 33(1), 79-100.

ZabA, B. \& PAes, N. (1995). An alternative procedure for fitting relational model life tables. Genus, LI(1-2), 19-43. 